JOSÉ RICARDO DE FREITAS ARCHILLA

AÇÃO DO LASER DE Nd:YAG INTRACANAL SOBRE ENDOTOXINAS NA DENTINA RADICULAR

São Paulo 
José Ricardo de Freitas Archilla

\section{Ação do laser de Nd:YAG intracanal sobre endotoxinas na dentina radicular}

Tese apresentada à Faculdade de Odontologia da Universidade de São Paulo para obter o título de Doutor pelo Programa de Pós-Graduação em Odontologia.

Área de Concentração: Dentística

Orientadora:

Prof $^{a}$. Dr ${ }^{a}$. Márcia Martins Marques

São Paulo 
Archilla JRF. Ação do laser de Nd:YAG intracanal sobre endotoxinas na dentina radicular [Tese de Doutorado]. São Paulo: Faculdade de Odontologia da USP; 2007.

São Paulo, / /

\section{Banca Examinadora}

1) $\operatorname{Prof}(a)$. $\operatorname{Dr}(a)$

Titulação:

Julgamento:

Assinatura:

2) $\operatorname{Prof}(a) \cdot \operatorname{Dr}(a)$

Titulação:

Julgamento:

Assinatura:

3)Prof(a). $\operatorname{Dr}(a)$

Titulação:

Julgamento:

Assinatura:

4)Prof(a). $\operatorname{Dr}(a)$

Titulação:

Julgamento:

Assinatura:

5)Prof(a). $\operatorname{Dr}(a)$

Titulação:

Julgamento:

Assinatura: 


\section{DEDICATÓRIA}

A meus pais, por suas vidas dedic adas aos filhos.

A meus immãos, que nosso espínito de família e união esteja sempre presente. 


\section{AGRADECIMENTOS}

À minha orientadora Prof ${ }^{a}$. Dr ${ }^{a}$. Márcia Martins Marques, Coordenadora do Programa de Pós-Graduação em Dentística, pelo prazer de ter sido seu orientado, pela paciência, competência e motivação constante.

Ao Prof. Dr. Carlos de Paula Eduardo, Diretor da Faculdade de Odontologia de São Paulo - FOUSP, mentor dos estudos na área do laser pelo incentivo constante.

Ao Prof. Dr. Antônio Carlos Bombana, Chefe do Departamento de Dentística da FOUSP e a todos os docentes, pela competência e por todos os ensinamentos recebidos.

Às Professoras Margareth Oda, Adriana Bona Matos, Miriam Lacalle Turbino e aos Professores Michel Nicolau Youssef e Antonio Alberto de Cara, pela amizade e orientação em muitas das minhas atividades acadêmicas.

Aos professores do LELO, Luciane Azevedo, Tanji, Sheila, Pelino, Ilíria, Ricardo Navarro, Tannous, Cláudia e Groth (in memorian ) pelos ensinamentos e amizade.

À Lili, à Jô e ao Haroldo pelo apoio e amizade no LELO.

Aos amigos do curso de Pós-Graduação, Vinicius, Robles, Ciça, Patrícia Freitas, Washington, Nino, Alessandra, Márcio, Beto, Alex, Bia, Arlene, Patty Lloret, Kátia, Thaís, Sheila e Ana Del Carmem pelos bons momentos compartilhados.

À Kátia, Alessandra e Nair, da Secretaria de Pós-Graduação

Aos funcionários da Faculdade de Odontologia da Universidade de São Paulo-USP, David, Ana, Neusa, Arnaldo, Sônia e Aldo pelo apoio constante. 
À Vânia Martins B. O. Funaro e à Maria Aparecida Pinto da Biblioteca da Faculdade de Odontologia da Universidade de São Paulo.

Aos amigos, incentivadores e colaboradores, Dr. Renato Vita, Dr. Sérgio Bellacosa, Dr. Afonso Henrique C. M. de Campos, José Quinto Jr, Dr ${ }^{a}$. Stella katayama e Dra . Andrea Ashcar Cury.

Ao Prof. Dr. Armando Mirage pela amizade e solicitude constante no IPEN

Ao Fábio do IME, pelo apoio nos cálculos.

À Prof ${ }^{a}$. Dr ${ }^{a}$ Silvia Celina Alfieri, à Ana Cristina e à Elizabeth do Laboratório de Biologia Celular e Bioquímica de Protozoários ICB II/USP meu agradecimento pela gentileza e cooperação.

Ao Dr. Paulo Rela e a Dra. Yasko Kodama pelo ajuda no processamento das amostras do experimento no Irradiador Multipropósito de Co 60 do IPEN.

Ao Instituto de Pesquisas Energéticas e Nucleares-IPEN.

Ao Dr. Paulo Leites pela colaboração com o Laser da Lares.

À Faculdade de Odontologia da Universidade de São Paulo-USP.

À FAPESP, pela concessão do Auxílio Pesquisa (2005/57550-6).

À CAPES, pela concessão da bolsa de estudo.

A todos que direta ou indiretamente me apoiaram durante todo este caminho. 
Archilla JRF. Ação do laser de Nd:YAG intracanal sobre endotoxinas na dentina radicular [Tese de Doutorado]. São Paulo: Faculdade de Odontologia da USP; 2007.

\section{RESUMO}

As endotoxinas são responsáveis por importantes reações sistêmicas e locais, podendo comprometer o sucesso do tratamento endodôntico. O hidróxido de cálcio, mesmo com limitações, mostra-se como opção única efetiva entre as soluções irrigadoras e as medicações intracanal na redução das endotoxinas nos túbulos dentinários. O experimento realizado avaliou a eficiência do laser de $\mathrm{Nd}$ :YAG frente à uma endotoxina inoculada no canal radicular pela utilização de duas cinemáticas de irradiação. Após um período de incubação, confirmada a passagem da endotoxina inoculada no canal radicular através da dentina e do cemento radicular, a irradiação foi realizada ou com cinemática oscilatória ou com cinemática helicoidal, para posterior leitura e comparação com os grupos controle. Os parâmetros utilizados na irradiação com o laser de Nd:YAG de comprimento de onda de 1064 nm foram: $100 \mathrm{~mJ}, 15 \mathrm{~Hz}, 1,5 \mathrm{~W}$, diâmetro do núcleo da fibra $320 \mu \mathrm{m}$, fluência do pulso $124 \mathrm{~J} / \mathrm{cm}^{2}$, largura do pulso $120 \mu \mathrm{s}$ e intervalo de relaxação térmica $30 \mathrm{~s}$. Os dados foram comparados pelo método ANOVA, complementado pelo teste de Tukey. As concentrações de endotoxina nos espécimes dos grupos irradiados (helicoidal e oscilatório) foram similares. Além disso, elas também foram similares às dos espécimes controle negativo e significantemente menores $(p=0,0271)$ que as do controle positivo, que não sofreram irradiação. A irradiação com laser de Nd: YAG, nas condições deste experimento é efetiva na inativação da endotoxina da dentina radicular.

Palavras-Chave: Endotoxina, Dentina, Laser de Nd:YAG 
Archilla JRF. Root canal Nd:YAG laser action on endotoxins in the radicular dentin [Tese de Doutorado]. São Paulo: Faculdade de Odontologia da USP; 2007.

\begin{abstract}
The endotoxins are responsible for important systemic and local reactions that could compromise the endodontic success. The calcium hydroxide even with limitations is the only effective option among the irrigant solutions and intracanal medications on the endotoxin reduction in the dentinal tubules. This experiment evaluated the $\mathrm{Nd}$ :YAG laser efficacy regarding the inoculated endotoxin in the root canal with two cinematic irradiation procedures. The irradiation was accomplished using an oscillatory and helicoidal technique after an incubation period where the passage of the inoculated endotoxin inside the root canal through dentin and cement was confirmed. Following this the analysis and comparison among the groups was performed. The Nd:YAG laser $(\lambda=1064 \mathrm{~nm})$ irradiation, used parameters were: $100 \mathrm{~mJ}, 15 \mathrm{~Hz}, 1,5 \mathrm{~W}$, core fiber diameter of $320 \mu \mathrm{m}$, pulse fluency of $124 \mathrm{~J} / \mathrm{cm}^{2}$, pulse width of $120 \mu \mathrm{s}$ and relaxation time interval of $30 \mathrm{~s}$. The data were statistically compared by ANOVA complemented by the Tukey's test $(p \leq 0,005)$. The endotoxin concentration at the irradiated samples, regardless the techniques applied were similar. Moreover these concentrations were also similar to those of negative controls and significantly smaller than those of positive controls that were not irratiated $(p=0,0271)$. The $N d: Y A G$ laser irradiation under this experiment conditions was effective on the root canal endotoxin inactivation.
\end{abstract}

Keywords: endotoxin, dentin, Nd:YAG laser 


\section{LISTA DE ABREVIATURAS E SIGLAS}

$\begin{array}{ll}\mu \mathrm{m} & \text { micrometro } \\ \mu \mathrm{s} & \text { microssegundo } \\ \mathrm{cm} & \text { centímetro } \\ \mathrm{Cm}^{2} & \text { centímetro quadrado } \\ \mathrm{EDTA} & \text { ácido etileno diamino tetracético } \\ \mathrm{Er}: \mathrm{YAG} & \text { érbio: ítrio, alumínio, granada } \\ \mathrm{He}: \mathrm{Ne} & \text { hélio-neônio } \\ \mathrm{Hz} & \text { hertz } \\ \mathrm{J} & \text { joule } \\ \mathrm{J} / \mathrm{cm}{ }^{2} & \text { joule por centímetro quadrado } \\ \mathrm{Laser} & \text { light amplification by stimulated emission of radiation } \\ \mathrm{mJ} & \text { milijoule } \\ \mathrm{mJ} / \mathrm{p} & \text { milijoule por pulso } \\ \mathrm{mm} & \text { milímetro } \\ \mathrm{NaOCl} & \text { hipoclorito de sódio } \\ { }^{\circ} \mathrm{C} & \text { nanômetro } \\ & \text { grau Celsius } \\ & \end{array}$




$\begin{array}{ll}\mathrm{pH} & \text { potencial de Hidrogênio } \\ \mathrm{S} & \text { segundo } \\ \mathrm{W} & \text { Watt } \\ \% & \text { comprimento de onda } \\ \mathrm{Nd}: Y A G & \text { porcentagem } \\ \text { Er:YAG } & \text { Érbio, Ítrio, Alumínio, Granada } \\ \text { Er,Cr:YSGG } & \text { Érbio, Cromo, Ítrio, Escândio, Gálio, Granada } \\ \mu \mathrm{ml} & \text { Micro litro } \\ \mathrm{ml} & \text { Mililitro }\end{array}$




\section{SUMÁRIO}

p.

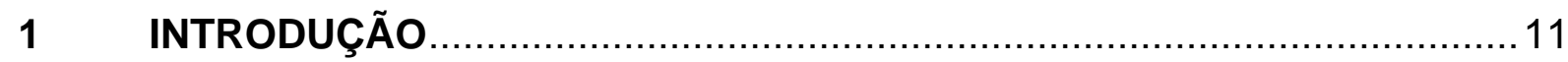

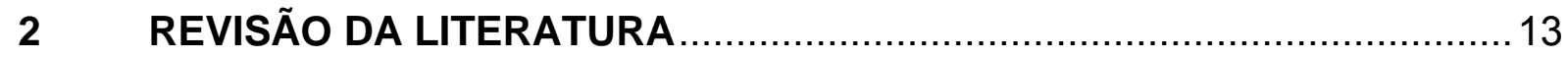

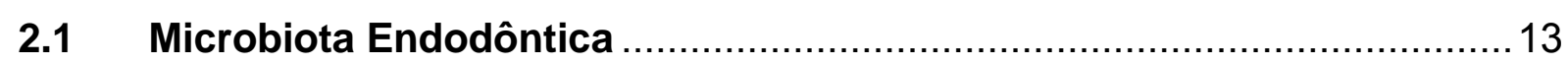

2.2 Soluções Irrigadoras e Medicação Intracanal ...................................... 18

2.2.1 Efeitos em endotoxinas............................................................... 21

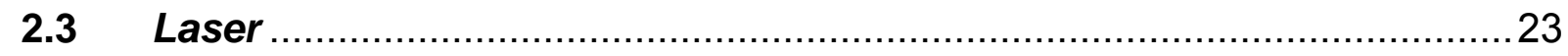

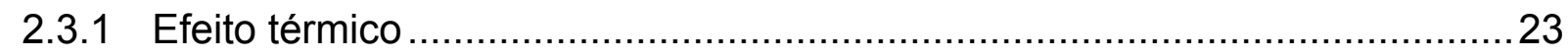

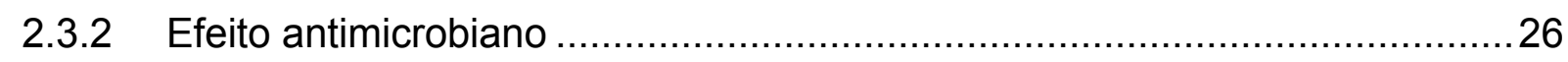

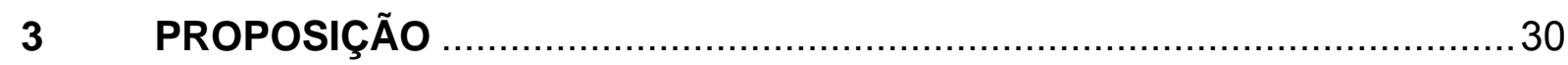

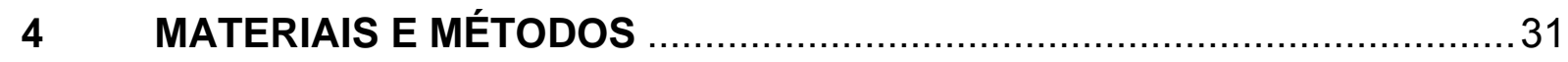

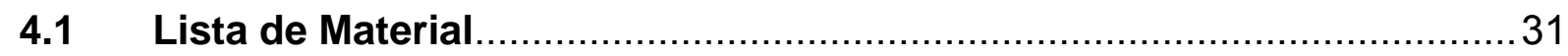

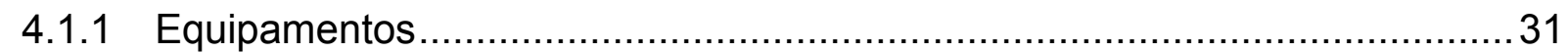

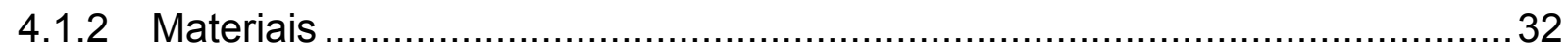

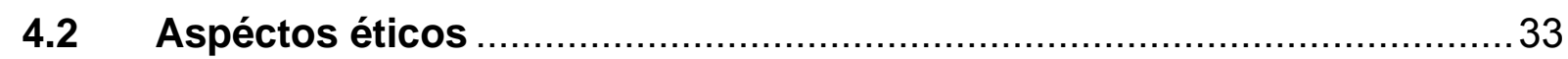

4.3 Seleção de Materiais e Método de Esterilização .................................... 33

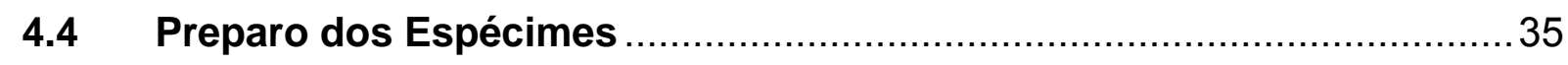

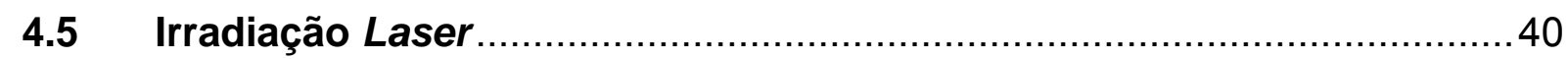

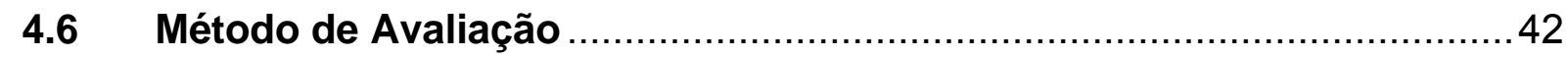

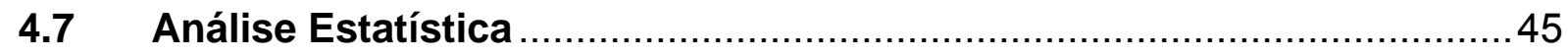

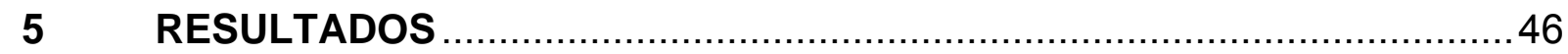

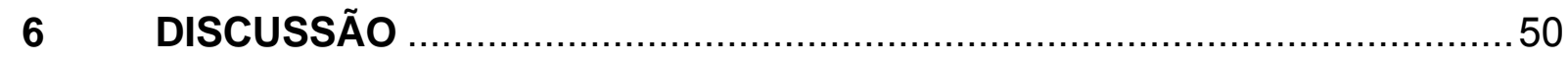

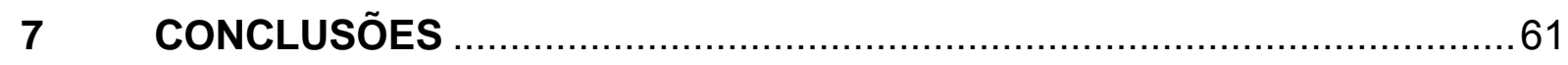

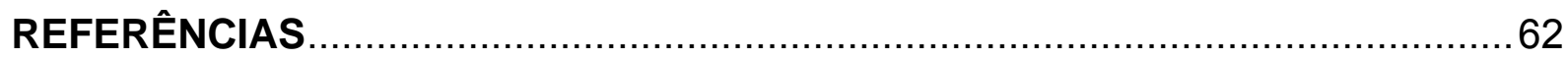

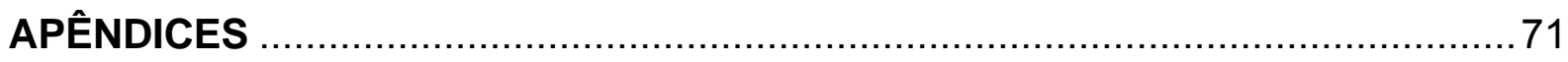

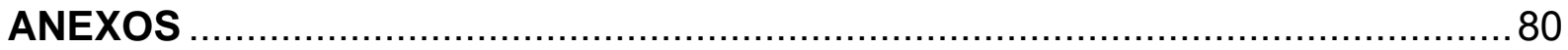




\section{INTRODUÇÃO}

A máxima redução dos microrganismos e de seus componentes constitui um fator determinante no sucesso da terapia endodôntica.

As endotoxinas bacterianas, presentes nas bactérias Gram-negativas, desempenham papel significante nos processos de inflamação, reabsorção óssea, sintomas clínicos e ativação do sistema complemento, além de possuírem habilidade de se difundir através da dentina humana e serem responsáveis por uma série de reações sistêmicas.

O hidróxido de cálcio, apesar das suas limitações, mostra-se como opção única efetiva entre as soluções irrigadoras e as medicações intracanal para obter a inativação ou redução da concentração das endotoxinas nos túbulos dentinários, de dentes portadores de necrose pulpar, até o presente momento.

A utilização do laser, como mais um meio auxiliar à terapia endodôntica, propicia desinfecção em maior profundidade de penetração no interior dos túbulos dentinários, se comparada aos agentes químicos e à medicação intracanal hoje utilizados durante e após o preparo químico-cirúrgico do sistema de canais radiculares. Verifica-se uma diminuição na sintomatologia pós-operatória, assim como uma diminuição no tempo de cura clínica das lesões ósseas radiograficamente discerníveis.

O laser de Nd:YAG possui parâmetros de operação consagrados na literatura e eficiência antimicrobiana até $1000 \mu \mathrm{m}$ de espessura de dentina. 
Com base no exposto, julga-se oportuno avaliar a eficácia do laser de $\mathrm{Nd}: Y A G$, frente às endotoxinas bacterianas, valendo-se de diferentes cinemáticas de aplicação. 


\section{REVISÃO DA LITERATURA}

\subsection{Microbiota endodôntica}

O principal fator etiológico causador da inflamação pulpar é a invasão de microrganismos e ou de seus componentes na polpa.

Em condições normais, o esmalte e o cemento protegem e isolam a dentina e a polpa da agressão microbiana. Quando um desses tecidos é perdido, criam-se condições favoráveis para a invasão microbiana no tecido pulpar.

A cárie dental é a via de entrada mais comum para a penetração de microrganismos e seus componentes no tecido pulpar, induzindo sucessivas respostas inflamatórias e culminando na necrose pulpar, caso não sejam adotadas as devidas medidas terapêuticas (BERGENHOLTZ; CRAWFORD, 1989; SUNDQVIST, 1992).

A contaminação também pode ocorrer por meio de fraturas, gretas, restaurações com infiltração, enfermidade periodontal, bruxismo, ocasionando desgaste do esmalte e exposição dentinária, ou pela corrente sangüínea, denominada via anacorética (LIN; LANGELAND, 1981; BERGENHOLTZ; CRAWFORD, 1989).

A elevada permeabilidade da dentina, com 30.000 a 70.000 túbulos por $\mathrm{mm}^{2}$, diâmetro de $1 \mu \mathrm{m}$ a $4 \mu \mathrm{m}$, ramificações laterais e anastomoses de $1 \mu \mathrm{m}$ (BHASKAR, 1978), viabilizam a difusão de bactérias como, por exemplo, os estreptococos com 0,5 a 0,75 micrometros de diâmetro das suas esférulas (BIER, 1982). 
Os microrganismos presentes nos canais radiculares infectados representam um grupo restrito de espécimes comparadas à flora total da cavidade oral. Mais de 509 espécies de bactérias são encontradas na cavidade oral, porém alguns fatores como a viabilidade nutricional, baixa tensão de oxigênio nas polpas necrosadas e interações bacterianas são determinantes na seleção da microbiota dos canais radiculares (LEONARDO et al., 1999; SELTZER; FARBER, 1994).

Embora, até o presente momento, não exista um método capaz de resgatar e quantificar todos microrganismos capazes de sobreviver no sistema de canais radiculares (GOMES et al., 2004), esses compõem um grupo diverso de microrganismos com 132 espécies isoladas (DEBELIAN; OLSEN; TRONSTAD, 1995). No entanto, a microbiota com polpa necrótica é dominada por bactérias anaeróbicas, das quais, usualmente, apenas de uma até 12 espécies de bactérias são encontradas no sistema de canais radiculares (FABRICIUS et al., 1982; SUNDQVIST, 1992; ØRSTAVIK; FORD, 1998).

Siqueira Jr (2001) investigou a razão dos insucessos de tratamentos endodônticos realizados conforme protocolo estabelecido. Na maioria dos casos, a falha do tratamento endodôntico foi o resultado de microrganismos que permaneceram na porção apical do sistema radicular. Os microrganismos remanescentes nutrem-se provavelmente do fluido tissular, que pode infiltrar-se em regiões não vedadas de dentes endodonticamente tratados com lesão perirradicular persistente. Como os microrganismos estabelecidos na região do tecido perirradicular são inacessíveis aos procedimentos de desinfecção endodôntica, a infecção extra-radicular pode ser um fator na falha da terapia endodôntica.

Os gêneros de bactérias mais freqüentemente isolados de polpas necrosadas são: Peptostreptococcus, Prevotella, Porphyromonas, Fusobacterium, Eubacterium, 
Actinomyces e Streptococcus facultativos (GOMES et al., 2004; GOMES; LILLEY; DRUCKER, 1996; JACINTO et al., 2003; SELTZER; FARBER, 1994; SUNDQVIST, 1992).

A partir da década de 90 , com o desenvolvimento de novas técnicas de identificação microbiana e da utilização de metodologias de genética molecular, outros microrganismos foram isolados em polpas necrosadas, como, por exemplo, Treponema denticola, Filifactor alocis e Tannerella forsythensis (GOMES et al., 2006; SIQUEIRA Jr et al., 2004).

Gomes et al. (2004) investigaram a flora bacteriana primária e secundária de canais infectados e a associação das espécies constituintes com sinais e sintomas específicos. Os resultados indicaram uma interação complexa, os quais não poderiam ser atingidos por uma única espécie.

As células de bactérias Gram-positivas, tais como Peptostreptococcus e Eubacterium spp., incluem peptideoglicanos e ácidos lipoteicóicos, os quais podem influenciar as reações inflamatórias e potencializar a patogenicidade dos Bacteróides de pigmento negro, estando também relacionados com os sintomas agudos e com a destruição dos tecidos periapicais (HASHIOKA et al., 1992; SUNDQVIST; JOHANSSON; SJOGREN, 1989).

Espécies Gram-negativas tais como Prevotella, Porphyromonas e Fusobacterium podem estar envolvidas no desenvolvimento da sintomatologia clínica devido à presença de endotoxinas, que podem estimular a produção de bradicinina, que é um importante mediador da dor (FARBER; SELTZER, 1988).

As espécies Gram-negativas possuem, estruturalmente, além da camada de peptideoglicano, outra camada mais periférica, denominada de membrana externa, localizada acima do peptideoglicano, que contém lipoproteínas e lipopolissacarídeos 
(ambos exclusivos de Gram-negativos). Os lipopolissacarídeos (LPS), quando liberados da célula Gram-negativa, por lise desta ou durante o processo de divisão celular (na forma de vesículas), são conhecidos como endotoxinas, sendo o lipídio $\mathrm{A}$ a porção da molécula principal responsável por seus efeitos (RIETSCHEL; BRADE, 1992) (Figura 2.1).

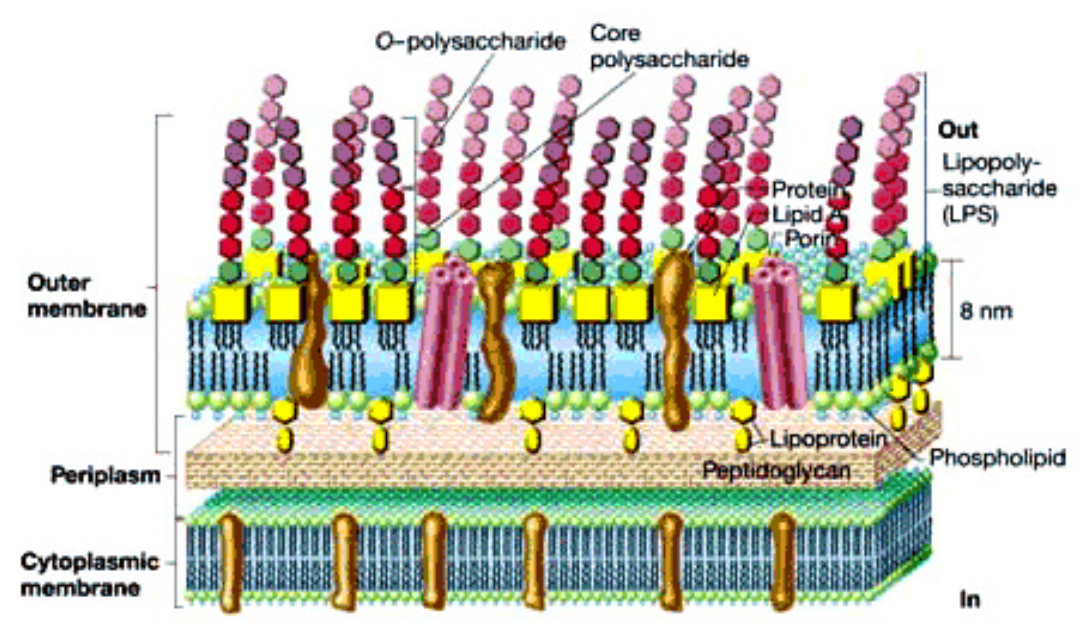

Figura 2.1 -Esquema da parede celular de organismos Gram-negativos (TORTORA; FUNKE; CASE, 1998)

A face exterior da membrana externa é rica em lipopolissacarídeos (LPS) (Figura 2.2), molécula complexa, composta por três regiões distintas: lipídeo A, polissacarídeo central e cadeia polissacarídica lateral O, ou antígeno O. O lipídeo A corresponde à porção tóxica do LPS e geralmente é composto por ácido esteárico, palmítico, mirístico, láurico ou capróico (MADIGAN; MARTINKO; PARKER, 2006). 


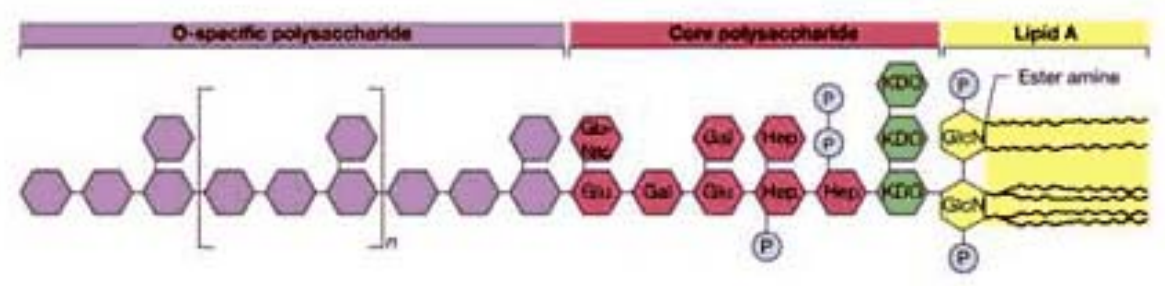

Figura 2.2 -Esquema do lipopolissacarídeo, encontrado na face exterior da membrana externa (TORTORA; FUNKE; CASE, 1998)

As endotoxinas exercem seus efeitos quando a bactéria Gram-negativa morre e sua parede celular sofre lise, liberando assim a endotoxina. e ocasionando uma piora imediata dos sintomas, mas, usualmente, com conseqüente melhora à medida que a endotoxina se degrada. Todas endotoxinas produzem os mesmos sinais e sintomas, independente da espécie de microrganismo, embora não na mesma intensidade. As respostas do hospedeiro incluem calafrios, febre, fraqueza, dores generalizadas, formação de coágulos, aborto e, em alguns casos, choque e mesmo morte (MADIGAN; MARTINKO; PARKER, 2006).

Acredita-se que a febre (resposta pirogênica) causada por endotoxinas ocorra quando bactérias Gram-negativas são ingeridas por células fagocíticas e degradadas em vacúolos, liberando LPS da parede celular bacteriana. Essas endotoxinas induzem a formação, pelos macrófagos, de pequenas moléculas protéicas denominadas interleucina-1 (IL-1) - anteriormente denominadas pirógeno endógeno - que são transportadas pelo sangue até o hipotálamo, centro de controle de temperatura no cérebro. A IL-1 induz o hipotálamo a liberar lipídios denominados prostaglandinas, que reajustam o termostato no hipotálamo a temperatura maior. O resultado é uma febre. A morte da célula bacteriana, causada por lise ou antibióticos, também pode produzir febre por este mecanismo (MADIGAN; MARTINKO; PARKER, 2006). 
Foi demonstrado que as endotoxinas bacterianas desempenham papel significante em processos como a inflamação ou reabsorção óssea (DAHLEN; MAGNUSSON; MOLLER, 1981; DWYER; TORABINEJAD, 1981; HOSOYA; MATSUSHIMA, 1997; JIANG et al., 2002; PITTS; WILLIAMS; MORTON, 1982; RAISZ et al., 1981; WESSELINK; THODEN VAN VELZEN; MAKKES, 1978), estão associadas a canais radiculares com sintomas clínicos e áreas periapicais radiolucentes (HORIBA et al., 1991; JACINTO et al., 2005; KHABBAZ; ANASTASIADIS; SYKARAS, 2000; KHABBAZ; ANASTASIADIS; SYKARAS, 2001; SCHEIN; SCHILDER, 1975; SCHONFELD et al., 1982; YAMASAKI et al., 1992), promovem a ativação do sistema complemento (HORIBA et al.,1992) e possuem habilidade de se difundirem através da dentina humana (HORIBA et al.,1990; NISSAN et al.,1995; OLIVEIRA et al., 2005a).

Murray e Saunders (2000) sugeriram que a bacteriemia ou a associação de endotoxinas bacterianas, subseqüentes à terapia endodôntica, podem causar complicações sistêmicas.

\subsection{Soluções Irrigadoras e Medicação Intracanal}

A máxima eliminação de bactérias do sistema de canais radiculares propicia ambiente favorável ao reparo dos tecidos perirradiculares, elevando, conseqüentemente, o índice de sucesso da terapia endodôntica em casos de necrose pulpar. $O$ emprego de medicação intracanal entre as sessões do tratamento 
endodôntico potencializa a desinfecção do sistema de canais radiculares, atuando, sobretudo, sobre microrganismos não afetados pelo preparo químico-cirúrgico.

Os microrganismos localizados em áreas como os istmos, ramificações, deltas, irregularidades, e túbulos dentinários não serão eliminadas somente por meios mecânicos. O uso de agentes químicos como a soluções irrigadoras e medicações antimicrobianas, entre as sessões, visando o controle desses microrganismos e melhor desinfecção do sistema de canais radiculares é de significativa importância (EL KARIM; KENNEDY; HUSSEY, 2007).

Várias substâncias têm sido preconizadas para uso como medicação intracanal. As mais comuns são os derivados fenólicos, aldeídicos e halogenados, além do hidróxido de cálcio e alguns antibióticos (SIQUEIRA Jr; DE UZEDA, 1997).

Apesar dos resultados positivos obtidos em pesquisa, utilizando o hidróxido de cálcio como medicação intracanal, é importante ressaltar que a presença de pó de dentina decorrente da instrumentação endodôntica cria um efeito inibitório sobre a ação dessa substância (HAAPASALO et al., 2000).

O tempo de permanência do hidróxido de cálcio no interior do canal também é um fator relevante à sua eficiência. Estrela et al. (1999) utilizando combinação de microrganismos Gram-negativos e Gram-positivos não obtiveram efeito antimicrobiano no período de até sete dias.

Apesar da adequação cada vez maior aos objetivos específicos dessa fase, não há fármaco que reúna a totalidade das condições ideais e dos requisitos básicos (LAGE MARQUES; ANTONIAZZI, 2000).

Siqueira Jr, Magalhães e Rôças (2007) enfatizam que os meios de cultura que apresentam resultados negativos, não implicam em esterilidade, pois podem ser resultado de limitações do protocolo experimental. Uma desvantagem do protocolo 
utilizado em vários estudos é que as amostras são obtidas somente no canal principal. Outras regiões do sistema de canais radiculares habitadas por bactérias podem não ser alcançadas nesse procedimento. Adicionalmente, as bactérias podem estar em níveis abaixo da sensibilidade dos métodos de cultura ou serem incapazes de crescer em condições artificiais de laboratório. Mesmo assim, os estudos têm mostrado que o prognóstico favorável do tratamento endodôntico aumenta significativamente quando os canais radiculares não apresentaram cultura de bacterianas positivas previamente à fase de obturação.

A busca de um produto ideal continua com o desenvolvimento de novos materiais e métodos devido às limitações encontradas nas soluções irrigadoras e nas medicações intracanal, tais como: ECA (Sterilox 2500), solução ativada eletroquimicamente, composta de uma solução catiônica, alcalina e com alto poder detergente e outra aniônica, com alto potencial de oxidação e propriedades antimicrobianas (SHETTY et al., 1999). O MTAD, composto de tetraciclina, ácido acético, e detergente, também foi introduzido como um material auxiliar na remoção do smear layer, com característica antimicrobiana (RUFF; MCCLANAHAN; BABEL, 2006; TORABINEJAD et al., 2003). A ozonização da água também tem sido pesquisada como solução irrigante devido a sua alta capacidade antimicrobiana, comprovando eficiência na desinfecção de túbulos dentinários, com baixa citotoxidade (NAGAYOSHI et al., 2003). 


\subsubsection{Efeitos em endotoxinas}

O objetivo do tratamento do sistema de canais radiculares de dentes com polpas necrosadas e lesões periapicais crônicas é baseado não somente na eliminação de microrganismos e substrato, mas também na inativação do efeito tóxico do LPS, importante para a cura dos tecidos periapicais (SILVA et al., 2002).

Entretanto, a preparação biomecânica do sistema de canais radiculares somente reduz parcialmente a microbiota endodôntica, não eliminando todos os microrganismos presentes no sistema (BERUTTI; MARINI; ANGERETTI,1997; LAGE MARQUES; ANTONIAZZI, 2000) e não inativando o LPS quando utilizada a clorexidina em concentrações de 0,12\% e 2\% (BUCK et al., 2001; GRENIER; BERTRAND; MAYRAND,1995; OLIVEIRA et al., 2007; SILVA et al., 2004; TANOMARU et al., 2003) ou quando se utilizam soluções de hipoclorito de sódio em concentrações de 1\% a 5,25\% (BUCK et al., 2001; BUTTLER; CRAWFORD, 1982; OLIVEIRA et al., 2007; SILVA et al., 2004; TANOMARU et al., 2003).

Oliveira et al. (2005b) e Oliveira et al. (2007) obtiveram resultados positivos na inativação do LPS quando utilizaram intracanal o polymyxin $B$, antibiótico que previne o efeito letal da endotoxina em vários animais, inibindo a coagulação intravascular e a reação generalizada de Shwartzman induzidas pelo LPS (EVANS; FEOLA; RAPP, 1999).

As substâncias químicas alcalinas, como o hidróxido de cálcio, neutralizam o LPS por meio de hidrólise do lipídio A, convertendo-o em ácidos graxos e açúcares atóxicos. Os resultados obtidos em diferentes metodologias mostraram-se eficientes. 
Safavi e Nichols (1993) obtiveram a inativação do LPS utilizando método de avaliação de liberação de ácido graxo. Os mesmos autores, Safavi e Nichols (1994), obtiveram a inativação do LPS mensurado pela secreção de prostaglandina $E_{2}$ de monócito humano.

O estudo de Buck et al. (2001) quantificou a inativação de até $27,5 \%$ de LPS, em um período de incubação do hidróxido de cálcio de cinco dias, calculada por uma estimativa de peso molecular.

Análises histopatológicas em ápices e tecidos periapicais em dentes de cachorro demonstraram padrão de normalidade na avaliação do infiltrado inflamatório, espessura do ligamento periodontal e reabsorção cementária e óssea na utilização do hidróxido de cálcio em presença de LPS (SILVA et al., 2002; TANOMARU et al., 2003).

O LPS induz a formação de osteoclastos e o hidróxido de cálcio inibe significativamente a sua formação. Segundo JIANG et al. (2003), esse pode ser um dos mecanismos pelo qual a utilização do medicamento entre consultas cria um ambiente favorável para a reparação óssea periapical.

Oliveira et al. (2005b) e Oliveira et al. (2007) em estudo in vitro obtiveram inativação do LPS, utilizando lisado de amebócito Limulus, após incubação do hidróxido de cálcio em canais unirradiculares em um período de sete dias. 


\subsection{Laser}

\subsubsection{Efeito térmico}

O laser tem se mostrado um poderoso coadjuvante no tratamento do sistema de canais radiculares, porém é importante a utilização adequada dos parâmetros corretos de energia do pulso, taxa de repetição, potência média, densidade de energia, largura do pulso, além do tempo de aplicação, tempo de relaxação térmica e análise de espessura da dentina remanescente após a instrumentação endodôntica para que se possam simultaneamente obter alto controle de desinfecção e baixos valores de aumento de temperatura, prevenindo assim danos térmicos à dentina, ao cemento e às fibras do ligamento periodontal da região apical.

O laser de Nd:YAG, com a emissão em 1.064 nanômetros, é pouco absorvido pela água e pela hidroxiapatita da dentina, possuidora de $12 \%$ de água em sua composição, o que assegura uma baixa absorção deste comprimento de onda.

Ericsson e Albrektsson (1983) avaliaram os limiares de temperatura que promovem injúria térmica ao tecido ósseo. Utilizaram 15 coelhos e em suas tíbias foram acopladas câmaras de temperatura. Em seguida, os animais foram divididos em três grupos e as mencionadas câmaras foram aquecidas a $50{ }^{\circ} \mathrm{C}$ por um minuto no grupo $\mathrm{A}$, a $47^{\circ} \mathrm{C}$ por cinco minutos no grupo $\mathrm{B}$ e a $47^{\circ} \mathrm{C}$ por um minuto no grupo C. Seqüencialmente, foram realizadas observações em microscópio para avaliar as respostas imediata e mediata do tecido ósseo. Os autores verificaram que o tecido ósseo aquecido a $50{ }^{\circ} \mathrm{C}$ por um minuto e a $47{ }^{\circ} \mathrm{C}$ por cinco minutos não se mantém 
funcional, sendo absorvido e substituído por células de gordura. O limiar para a manutenção da vitalidade do tecido ósseo é de $47{ }^{\circ} \mathrm{C}$ por um minuto. Portanto, a temperatura crítica para o dano ósseo é de $47^{\circ} \mathrm{C}$, ou seja, apenas $10^{\circ} \mathrm{C}$ acima da temperatura corpórea humana, sendo importante o fator tempo.

Os mesmos autores (ERICSSON; ALBREKTSSON 1983), avaliando o efeito da temperatura na regeneração óssea, realizaram um estudo, em que foi implantado titânio em tíbias de coelhos, posicionando um termopar a 0,5 mm do implante. Quatro grupos foram criados: o primeiro foi aquecido a $50{ }^{\circ} \mathrm{C}$ por um minuto, o segundo a $47{ }^{\circ} \mathrm{C}$ por um minuto, o terceiro a $44{ }^{\circ} \mathrm{C}$ por um minuto e o quarto não recebeu aquecimento. Após quatro semanas, os animais foram sacrificados e verificou-se que em termos de retenção o terceiro grupo apresentou a mesma dificuldade para remoção dos implantes que a do grupo sem aquecimento, fato confirmado mediante a densitometria. Pelo controle histológico não se verificou diferença qualitativa entre o grupo aquecido a $47^{\circ} \mathrm{C}$ e o grupo aquecido a $44^{\circ} \mathrm{C}$.

Esses dois trabalhos serviram de referência para novas pesquisas que avaliaram diversos parâmetros, tendo como limite máximo o aumento da temperatura de $10{ }^{\circ} \mathrm{C}$ na superfície radicular.

Bahcall et al. (1992) analisaram o efeito histológico do tratamento endodôntico com laser de Nd:YAG em tecido periapical de cachorros com os parâmetros de $3 \mathrm{~W}$ e $25 \mathrm{~Hz}$. Observou-se que um dia após o tratamento verificava-se necrose no ligamento periodontal, após 15 dias ocorriam sinais de reabsorção óssea, após 30 dias ocorriam anquilose, lise cementária e remodelação óssea. Anic, Tachibana e Masumoto (1996) compararam permeabilidade, morfologia e alterações térmicas dos lasers de $\mathrm{Nd}: \mathrm{YAG}, \mathrm{CO}_{2}$ e argônio. Verificaram que a temperatura máxima ocorreu em $30 \%$ dos casos na região cervical, em outros $30 \%$ na região apical e nos $40 \%$ 
restantes, no terço médio da superfície externa radicular. Nesse trabalho não houve um controle da espessura remanescente da dentina após o tratamento endodôntico. Com a aplicação de três segundos em movimentação ápicocoronária, 1 W e freqüência de $20 \mathrm{~Hz}$ ocorreu um aumento máximo de temperatura de $17,9^{\circ} \mathrm{C}$.

Utilizando outros parâmetros, novos estudos obtiveram aumentos de temperatura dentro dos limiares de segurança.

Behrens et al. (1993) avaliaram o aumento de temperatura em diferentes espessuras de dentina durante a utilização do laser de Nd:YAG. Concluíram que, quando a energia utilizada correspondia à recomendada para o tratamento de dentina (10 Hz, $80 \mathrm{~mJ}$ e $15 \mathrm{~Hz}, 150 \mathrm{~mJ}$ ), o aumento de temperatura não causaria danos aos tecidos vizinhos.

Khan et al. (1997) avaliaram as modificações térmicas e morfológicas na porção apical de dentes humanos extraídos tratados com o laser de Nd:YAG, $\mathrm{CO}_{2} \mathrm{e}$ argônio. A microscopia eletrônica mostrou que a energia utilizada vaporizou os debris depositados, produzindo uma superfície vitrificada. As maiores alterações térmicas foram produzidas pelo laser de argônio.

Utilizando a fibra do laser de Nd:YAG em movimento cérvico-apical-cervical, Ramskold, Fong e Stromberg (1997), nos parâmetros de 3 W, $50 \mathrm{~Hz}$ e $60 \mathrm{~mJ}$ durante 15 segundos, com 15 segundos de relaxação térmica, largura de pulso de 0,8 ms e fibra com 300 micrometros de diâmetro posicionada a $2 \mathrm{~mm}$ do ápice, verificaram um aumento de temperatura de até $6{ }^{\circ} \mathrm{C}$, com aferições realizadas a 7 $\mathrm{mm}$ do ápice.

Lan (1999) avaliou a elevação de temperatura na superfície radicular. Nos canais de 90 dentes, o terço apical foi irradiado pelo laser de $\mathrm{Nd}$ :YAG nos parâmetros de $50 \mathrm{~mJ} /$ pulso a $200 \mathrm{~mJ} /$ pulso e $20 \mathrm{~Hz}$ a $30 \mathrm{~Hz}$ e as temperaturas, 
dessa forma alcançadas, foram aferidas por um termopar localizado externamente à raiz. O aumento de temperatura não excedeu o limiar de $10{ }^{\circ} \mathrm{C}$ quando a energia esteve abaixo de $100 \mathrm{~mJ} /$ pulso e $20 \mathrm{~Hz} ; 80 \mathrm{~mJ} /$ pulso e $25 \mathrm{~Hz}$; ou $60 \mathrm{~mJ} /$ pulso e 30 $\mathrm{Hz}$, sempre aplicados por menos de 15 segundos.

A influência da cinemática de aplicação do laser de Nd:YAG nas variações de temperatura, quando comparadas as técnicas aplicadas por Gutknecht (GUTKNECHT et al., 1996b) e Matsumoto (ANIC; TACHIBANA; MATSUMOTO, 1996) e uma técnica com movimento oscilatório foi analisada por Archilla (2001). Todas as técnicas utilizadas estavam dentro dos padrões de segurança e a técnica oscilatória proporcionou melhor distribuição de calor durante a irradiação do laser.

\subsubsection{Efeito antimicrobiano}

A elevada permeabilidade da dentina (BHASKAR, 1978), a pequena dimensão dos microrganismos (BIER, 1982) e a limitação dos agentes químicos em combatê-los à distância tornam o laser um aliado na desinfecção do sistema de canais radiculares.

Utilizando parâmetros de segurança térmica, comprovados na literatura, vários estudos, descritos a seguir, com diferentes microrganismos foram realizados para validar a utilização do laser de Nd:YAG intracanal.

Em um estudo clínico, Gutknecht et al. (1996a) trataram endodonticamente 517 dentes com seleção estrita do material (em análise radiográfica existia presença de lesões com cinco $\mathrm{mm}$ de diâmetro ou mais). A 
radiação laser de Nd:YAG foi realizada no canal radicular através de uma fibra óptica de quartzo de 200 micrometros, com 1,5 W e $15 \mathrm{~Hz}$. Os critérios de avaliação do sucesso do tratamento foram: redução da radiolucidez apical em período de até doze meses, ausência de queixas, percussão negativa e conforto oclusal quando submetido à carga. O sucesso obtido com este critério foi de $82 \%$.

Os mesmos autores, Gutknecht et al. (1996b), utilizando bactéria Grampositiva, em dentes extraídos, realizaram aplicação do laser de Nd:YAG com fibra óptica de 200 e 300 micrometros, $15 \mathrm{~Hz}, 100$ mJ, 1,5 W, quatro vezes, durante dez segundos cada aplicação, em movimento helicoidal apicocoronário. Obtiveram como resultado médio 99,91\% de eliminação de microrganismos.

A redução bacteriana intracanal in vitro do laser de $\mathrm{Nd}$ :YAG também foi avaliada por Moritz et al. (1999), que compararam com os efeitos dos lasers de Ho;YAG e de Er:YAG, em dentes inoculados com Escherichia coli e Enterococcus faecallis. Os canais foram irradiados com $0,8 \mathrm{~W}, 10 \mathrm{~Hz}$ e $1,5 \mathrm{~W}, 15 \mathrm{~Hz}$, respectivamente com um grupo-controle permanecendo sem irradiação. $O$ procedimento foi repetido cinco vezes por cinco segundos, com 20 segundos de intervalo. Foram colhidas amostras para exame microbiológico, as quais obtiveram uma eliminação bacteriana de 99,64\% para o laser de Er:YAG, 99,16\% para o laser de Nd:YAG e 99,05\% para o laser de Ho:YAG.

A eficiência da utilização do laser na redução microbiana à distância foi avaliada por Klinke, Klimm e Gutknecht (1997), utilizando Streptococcus mutans em fatias de dentina de 100 a 1000 micrometros de espessura. Aplicaram o laser de $\mathrm{Nd}$ :YAG, com os parâmetros de $1,5 \mathrm{~W}, 15 \mathrm{~Hz}$, em uma angulação de $5^{\circ}$ com uma fibra de transmissão de 200 micrometros. Apesar da intensidade da irradiação do laser decrescer com o aumento da espessura das fatias de dentina, o efeito 
bactericida continuou eficaz. O percentual de redução de bactérias variou de $84,8 \%$ a 93,9\%. Posteriormente, Berkiten, Berkiten e Okar (2000) avaliaram o efeito antibacteriano do laser de Nd:YAG com 1,8W e $30 \mathrm{~Hz}$, durante 30 segundos nos canais radiculares e nos túbulos dentinários. Utilizaram amostras contaminadas com Streptococcus sanguis e Prevotella intermidia. Pela microscopia de luz e eletrônica de varredura foi demonstrado que houve uma redução de $86,3 \%$ de Streptococcus sanguis e uma esterilização de Prevotella intermídia.

O efeito bactericida dos lasers de Nd:YAG a $1 \mathrm{~mm}$ espessura foi comparado por Schoop et al. (2004) com os lasers de diodo de 810 nanômetros, Er:YAG e Er,Cr:YSGG, com os mesmos parâmetros de 1,5 W, $15 \mathrm{~Hz}$ e sem a utilização de refrigeração. As bactérias utilizadas foram Escherichia coli e Enterococcus faecallis. Ocorreu uma redução significativa de E. coli em todos os lasers, porém somente os lasers de Er:YAG e de diodo foram capazes de reduzir E. faecallis a um nível significativo.

A avaliação do efeito da irradiação na estrutura celular de bactérias Gramnegativas e Gram-positivas através da dentina foi estudada por Moritz et al. (2000). Os resultados mostraram que nas irradiações em que ocorreu imediata destruição estrutural nas bactérias Gram-negativas houve necessidade de repetição do ciclo de aplicação $(1,5 \mathrm{~W}, 15 \mathrm{~Hz}$, durante cinco segundos, cinco vezes com intervalo de 15 segundos) nas bactérias Gram-positivas. Constatou-se que a construção da parede celular é crucial na sensibilidade do tratamento com laser. A elevação de temperatura monitorada foi de $4,3^{\circ} \mathrm{C}$. Utilizando a mesma metodologia, porém com outras bactérias Gram-positivas, um ciclo de apenas quatro aplicações, e repetições de até três ciclos, Bergmans et al. (2006) confirmaram a necessidade de mais ciclos 
de aplicação e também constataram a dificuldade de erradicar o biofilme com o laser de Nd:YAG.

Os efeitos deletérios das endotoxinas são notórios, relatados em várias pesquisas. Até o presente momento, o hidróxido de cálcio mostra-se como única opção efetiva entre as soluções irrigadoras e as medicações intracanal, apesar da sua dependência em relação ao tempo de permanência e a necessária ausência de smear layer. O laser mostra-se eficiente na redução de bactérias Gram-negativas à distância, o que desperta interesse e justifica o estudo da sua atuação frente às endotoxinas. 


\section{PROPOSIÇÃO}

Constitui objetivo do presente experimento analisar a eficácia da irradiação do laser de Nd:YAG utilizando duas cinemáticas na redução da concentração de endotoxinas na dentina radicular. 


\section{MATERIAIS E MÉTODOS}

\subsection{Lista de Material}

\subsubsection{Equipamentos}

> Agitador ( Vortex Genie Z Fisher, EUA).

> Cabina de Proteção Biológica, modelo VLFS-09 (Veco, Campinas, SP, Brasil).

$>$ Cronógrafo sonorizado (Timex, Amazonas, Brasil).

> Cronômetro (Timex, Amazonas, Brasil).

$>$ Estufa para esterilização a $250^{\circ} \mathrm{C}$ (Fanem, São Paulo, Brasil).

> Hardware de radiografia digital (Schick Technologies NY, EUA).

> Irradiador Multipropósito de Co 60 (IPEN, São Paulo, Brasil).

> Laser de Nd:YAG Lares PowerLase ${ }^{\mathrm{TM}}$ (Lares Research, CA, EUA).

> Leitora Tecan Sunrise (Tecan Corp, Áustria, Europa).

> Micropipetas P 1000, P 200. (Gilson, França).

Dicropepitador multicanal Eppendorf (Eppendorf, Hamburgo, Alemanha, Europa).

$>$ Microscópio de luz (D. F. Vasconcellos, São Paulo, Brasil).

> Monitor de potência e energia Nova (Ophir, Jerusalém, Israel).

> Raio X Spectro II (Dabi Atlante, São Paulo, Brasil)

$>$ Sensor de radiografia digital (Schick Technologies NY, EUA).

> Sensor de potência e energia Ophir 3AP (Ophir, Jerusalém, Israel).

$>$ Software de radiografia digital (Schick Technologies NY, EUA). 


\subsubsection{Materiais}

$>$ Ácido etilenodiaminotetracético a $17 \%$, tamponado em $\mathrm{pH}=7$, com solução de hidróxido de sódio a 40\% (Fórmula \& Ação, São Paulo, Brasil).

> Água (sem pirogênio) (Associates of Cape Code Incorporated, East Falmouth, MA EUA).

D Brocas Axxess 0,20/0,6 e 0,35/0,6 (SybronKerr, CA, EUA).

> Cera utilidade (Clássico, São Paulo, Brasil).

> Cola Araldite ${ }^{\circledR}$ (Brascola Ltda, São Paulo, Brasil).

> Cones de papel absorvente estéril (Dentsply, York, PA, EUA).

> Discos diamantados (Vortex, São Paulo, Brasil).

$>$ Endotoxina Escherichia coli (Associates of Cape Code Incorporated, East Falmouth, MA, EUA).

> Fibra óptica de 300 micrometros (Lares PowerLase ${ }^{\mathrm{TM}}$, Lares Research, CA, EUA).

> Hipoclorito de sódio a 2,5\%, estabilizado com cloreto de sódio (Fórmula \& Ação, São Paulo, Brasil).

$>$ Limas Nitiflex (Maillefer Ballaigues, Suíça).

$>$ Papel alumínio.

$>$ Parafilme $\mathrm{M}^{\circledR}$ (American National Can, IL, EUA).

> Placas de microtitulação apirogênicas de poliestireno para 96 testes Pyroplate Pyroclear (Associates of Cape Code Incorporated, East Falmouth, MA, EUA).

$>$ Plástico de polietileno de gramatura $0,2 \mathrm{~mm}$. 
> Ponteiras apirogênicas para micropipetas de polipropileno Pyroclear de $250 \mu \mathrm{l}$ e $1000 \mu \mathrm{l}$ (Associates of Cape Code Incorporated, East Falmouth, MA, USA).

Drovetas de vidro de borosilicato de $25 \mathrm{ml}$ (Pyrex, NY, EUA).

> Pyrotell-T. Lisado de Amebócito Limulus (Associates of Cape Code Incorporated, East Falmouth, MA, EUA).

> Tubos de poliestireno (Greiner, Alemanha).

> Tubos de vidro de borosilicato Pyrotubes-D apirogênicos $10 \mathrm{~mm} \times 75 \mathrm{~mm}$ (Associates of Cape Code Incorporated, East Falmouth, MA, EUA).

> Vidros de borossilicato de $10 \mathrm{ml}$ (Sama vidros, São Paulo, Brasil).

$>$ Vinte e quatro dentes humanos superiores unirradiculares

\subsection{Aspectos Éticos}

Este estudo foi conduzido após aprovação do Comitê de Ética em Pesquisa da Faculdade de Odontologia da Universidade de São Paulo, conforme protocolo $\mathrm{n}^{\circ}$ 174/04 (Anexo A)

\subsection{Seleção de Materiais e Método de Esterilização}

O plástico à base de polipropileno interfere na leitura das endotoxinas (NOVITSKY; SCHMIDT-GENGENBACH; REMILLARD, 1986; ROSLANSKY; DAWSON; NOVITSKY, 1991; TWOHY; DURAN; PEELER, 1986), portanto foi 
utilizado, neste experimento, somente poliestireno, à exceção das ponteiras de polipropileno, pois o mercado não disponibiliza outra opção e permanecem por um período muito curto em contato com as amostras, não alterando a leitura.

O vidro de borossilicato foi utilizado devido a sua melhor performance em testes turbidimétricos quando comparado ao vidro de silicato de chumbo (NOVITSKY; SCHMIDT-GENGENBACH; REMILLARD, 1986; ROSLANSKY; DAWSON; NOVITSKY, 1991).

Para obter uma barreira de isolamento de difusão de endotoxinas nas amostras foi utilizada a cera utilidade (SOUZA, 2000; TROPE; CHOW; NISSAN, 1995).

Nos procedimentos de esterilização, optamos pelo calor seco, em estufa, à $250{ }^{\circ} \mathrm{C}$, durante 1 hora (LUDWIG; AVIS, 1990; NAKATA, 1993; NAKATA, 1994), e para os materiais sensíveis ao calor utilizamos radiação Gama $\left({ }^{60} \mathrm{Co}\right)$. A redução de endotoxinas nesse processo é tanto maior quanto maior a radiação, porém é importante considerar a tolerância dos produtos a esses aumentos, que podem causar enfraquecimento da estrutura, alteração de cor, odor e rompimento das embalagens. Como a cera utilidade utilizada no experimento não constava em tabelas de compatibilidade de materiais à radiação ionizante, previamente à irradiação foram realizados testes com doses distintas e verificadas as suas alterações (Figura 4.1). 


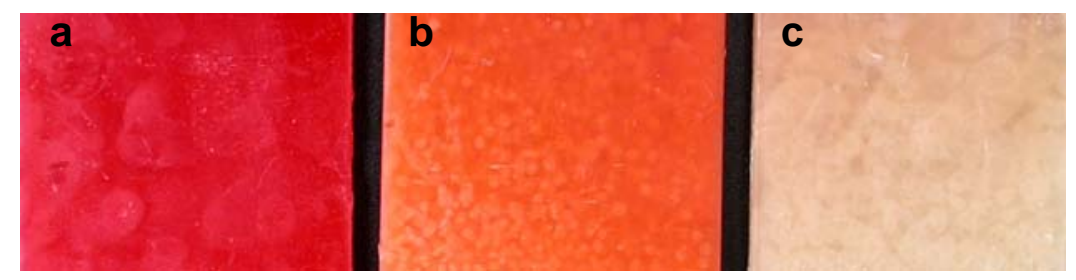

Figura 4.1 - Alterações de cor na cera utilidade provocadas por doses de irradiação distintas: a - sem irradiação; b - 30 KGy; c- 40 KGy

A dose utilizada no material do experimento foi de 3 Mrad (30 kGy) (CSAKO et al.,1983; WHITE et al., 1994) em embalagens de polietileno, com gramatura de 0,2 milímetros e a irradiação foi realizada no Irradiador Multipropósito de Co-60 do IPEN.

\subsection{Preparo dos Espécimes}

Foram selecionados 24 dentes humanos, caninos superiores e inferiores, totalmente formados, extraídos por motivos diversos e fornecidos pelo Banco de Dentes Humanos da Faculdade de Odontologia da Universidade de São Paulo, armazenados em água milliQ, esterilizada em filtros com poros de 0,22 $\mu \mathrm{m}$ (STRAWN et al., 1996).

Os dentes foram imersos em solução de hipoclorito de sódio a 1\% durante seis horas para desinfecção e os tecidos moles e cálculos porventura existentes foram cuidadosamente removidos com raspadores periodontais. Posteriormente, foram realizadas radiografias pré-operatórias para verificar se os dentes possuíam canal único e reto, calcificações ou reabsorções internas, sendo esses últimos 
considerados fatores excludentes. Foi realizada minuciosa inspeção na superfície externa radicular utilizando-se de um microscópio de luz com magnificação de oito vezes, na qual a presença de trincas ou a descontinuidade da camada cementária também foram consideradas fatores excludentes.

A coroa e parte da porção cervical de cada dente foram removidas por corte com a utilização de discos diamantados (Vortex, São Paulo, SP, Brasil) para que cada raiz ficasse com comprimento de $15 \mathrm{~mm}$, determinados pela introdução de uma lima tipo $\mathrm{K}$ de fino calibre até que sua guia de penetração fosse visualizada no forame apical com auxílio de um microscópio. O comprimento de trabalho foi obtido pela subtração de $1 \mathrm{~mm}$.

Em continuidade, foi realizado preparo químico-cirúrgico com limas Nitiflex (Maillefer, Suíça) e solução de hipoclorito de sódio a 2,5\%, complementando-se a remoção do magma dentinário com solução de EDTA a 17\% e irrigação final com água milliQ, esterilizada em filtros com poros de $0,22 \mu \mathrm{m}$.

Os canais foram preparados pela técnica seriada, com lima número 45 sob constante renovação de solução de hipoclorito de sódio a $2,5 \%$ a cada troca de instrumento, sendo que brocas Axxess 0,20/0,6 e 0,35/0,6 (SybronKerr, Ca, EUA) foram utilizadas na preparação dos terços coronário e médio.

Após a instrumentação, os dentes foram acondicionados em frascos de vidro individuais com água milliQ, esterilizada em filtros com poros de 0,22 $\mu \mathrm{m}$. Previamente à impermeabilização, estes foram secos na superfície externa com gaze previamente esterilizada e nos canais radiculares com cones de papel absorventes esterilizados (Dentsply, PA, EUA).

Vinte e um dentes foram impermeabilizados em cinco milímetros na porção cervical e cérvico-oclusal da superfície radicular externa com cera utilidade ${ }^{\circledR}$ e 
posicionados no interior do tubo de poliestireno e na região apical sobre tampão apical com $1 \mathrm{~mm}$ de dentina colado com resina epoxi (Araldite ${ }^{\circledR}$, Brascola Ltda, São Paulo, Brasil).

Três dentes foram impermeabilizados em toda superfície radicular externa com cera utilidade (grupo controle negativo).

Após o encaixe dos dentes nos tubos de poliestireno cortados em sua extremidade, a impermeabilização de interface dente/tubo foi realizada com cera utilidade (Figura 4.2).

Nos dentes posteriormente submetidos à irradiação laser foi refeita a condutometria, a partir da parte superior do tubo de poliestireno com auxílio de uma lima tipo $\mathrm{K}$ de número15.

Os espécimes assim montados foram embalados em plástico de polietileno e esterilizados por radiação Gama $\left({ }^{60} \mathrm{Co}\right)$ com 3 Mrad (30 kGy).

Em seguida, o conjunto dente e tubo de poliestireno (câmara superior) foi colocado em um recipiente de vidro de borosilicato (câmara inferior) previamente esterilizado em estufa a $250^{\circ} \mathrm{C}$ por uma hora. Foram adicionados $9 \mathrm{~mL}$ de água livre de pirogênio nas câmaras inferiores e $500 \mu \mathrm{L}$ nas câmaras superiores de todos os espécimes (controles e experimentais) (Figura 4.3). A porção superior e inferior das câmaras foram vedadas com parafilme (American National Can, IL, EUA). Vale ressaltar que todos os procedimentos e manipulação dos espécimes foram realizados com material esterilizado em estufa a $250{ }^{\circ} \mathrm{C}$ por 1 hora ou radiação Gama $\left({ }^{60} \mathrm{Co}\right)$ com $3 \mathrm{Mrad}(30 \mathrm{kGy})$ em ambiente de fluxo laminar (Veco, Campinas, SP, Brasil. Projeto Fapesp 2005/57550-6), com luvas cirúrgicas para prevenir a contaminação dos espécimes. 

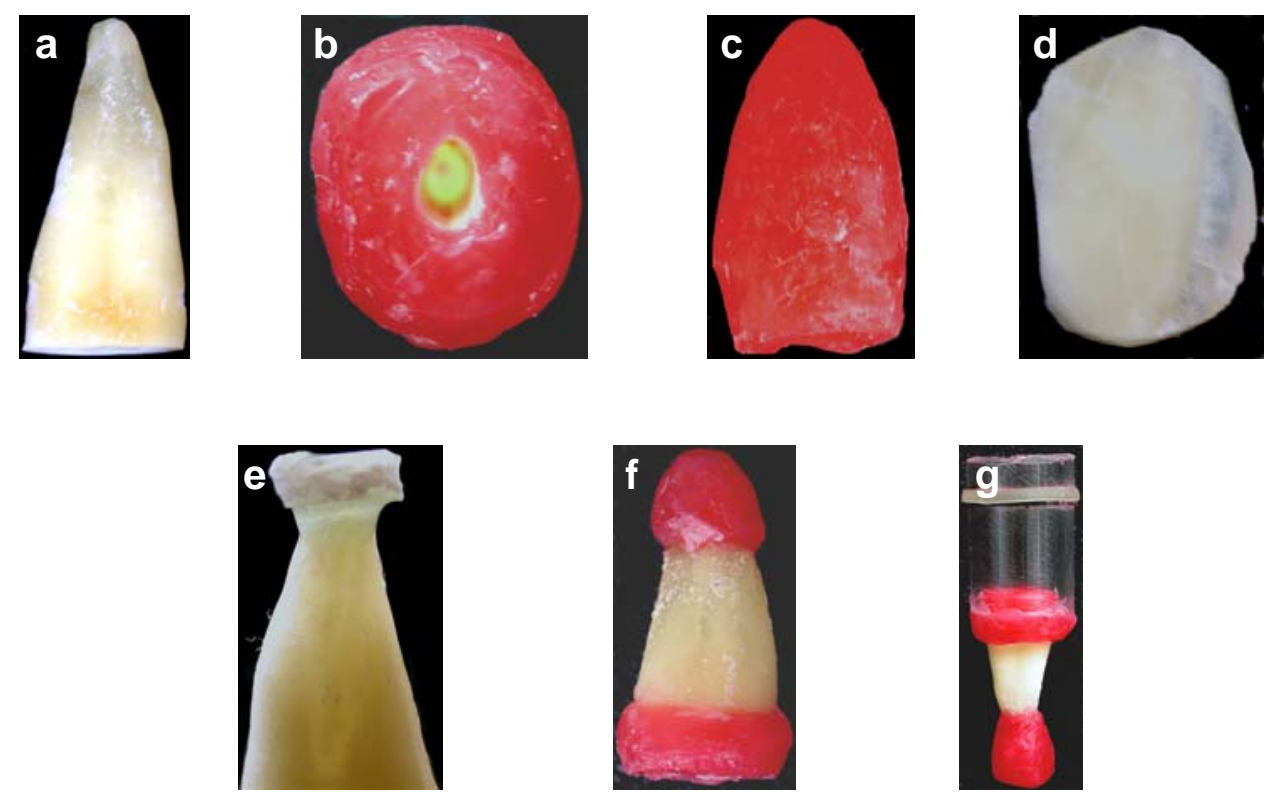

Figura 4.2 - Preparo das amostras: a - raiz cortada em $15 \mathrm{~mm}$; b impermeabilização cérvico-oclusal de todas as amostras; c controle negativo; d - tampão apical; e - colagem do tampão apical; $\mathrm{f}$ - impermeabilização cervical e apical do controle positivo e dos grupos experimentais; g - encaixe dos dentes nos tubos de poliestireno e impermeabilização de interface dente/tubo

Após 72 , horas $200 \mu \mathrm{L}$ de água foram removidos das câmaras e testados para a detecção de endotoxinas $(\geq 0,001 \mu \mathrm{g} / \mathrm{ml})$. Os conjuntos com presença de endotoxinas foram substituídos, submetidos à radiação gama e reavaliados.

Foi retirado todo o líquido da câmara superior com cânula de aspiração e os canais radiculares secados com cones de papel. Na câmara inferior foi acrescentada água livre de pirogênio para repor o volume da amostra retirada. 


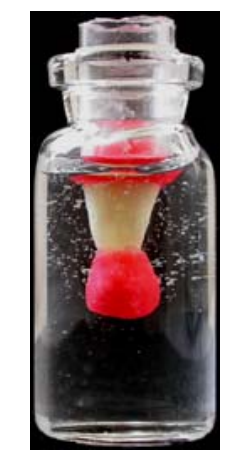

Figura 4.3 - Câmara superior e câmara inferior com água livre de pirogênio

Nesse experimento foi utilizada a endotoxina pura de E. coli (Associates of Cape Code Incorporated, East Falmouth, MA, EUA). Para tanto, a endotoxina pura (liofilizada) foi reconstituída e diluída e, em seguida, foram colocados $500 \mu \mathrm{L}$ na câmara superior na proporção de 16 UE /mL, com auxílio de micropipetas.

A avaliação foi realizada por meio de análise das amostras coletadas na câmara inferior a cada 24 horas de incubação em temperatura ambiente.

Após 48 horas evidenciou-se a passagem de endotoxinas em todas as amostras, à exceção daquelas do controle negativo. Confirmada a estabilização do processo após 72 horas foi realizado o esvaziamento das câmaras superior e inferior e os canais radiculares foram secados com cone de papel absorvente. Após a irradiação laser, todas as câmaras inferiores foram trocadas por outras previamente esterilizadas, contendo $9 \mathrm{~mL}$ de água apirogênica e a porção superior e inferior das câmaras vedadas com parafilme (American National Can, IL, EUA). Decorridas 72 horas de incubação em temperatura ambiente, nova avaliação de análise de amostras coletadas na câmara inferior foi realizada. A endotoxina infiltrada foi avaliada pelo teste LAL (Lisado de Amebócito Limulus), turbidimétrico cinemático Pyrotell-T (Associates of Cape Code Incorporated, East Falmouth, MA, EUA). 
Os dentes foram distribuídos em grupos da seguinte maneira:

Grupo 1: Os dentes $(n=9)$ foram submetidos à irradiação de laser de Nd:YAG acorde cinemática preconizada por Gutknecht (1996b) (partindo do preparo apical com movimento helicoidal em direção cervical à velocidade de $2 \mathrm{~mm} / \mathrm{s}$ ).

Grupo 2: Os dentes $(n=9)$ foram submetidos à irradiação de laser de Nd:YAG em movimentos oscilatórios apical-cervical-apical de duração de um segundo cada movimento, com o tempo proporcional à metade do comprimento do canal radicular.

Grupo positivo: Os dentes $(n=3)$ não foram irradiados.

Grupo negativo: Os dentes $(n=3)$ que foram totalmente impermeabilizados e que não foram irradiados.

\subsection{Irradiação Laser}

A partir do momento em que se constatou a presença de endotoxina em todas as amostras analisadas, os dentes dos grupos 1 e 2 foram irradiados com o laser de Nd:YAG Lares PowerLase ${ }^{\mathrm{TM}}$ (Lares Research, CA, EUA), com comprimento de onda de $1.064 \mathrm{~nm}$, largura de pulso de $120 \mu \mathrm{s}$, fibra óptica de sílica de $320 \mu \mathrm{m}$ de diâmetro do núcleo, utilizada de modo contato, com os parâmetros: $1,5 \mathrm{~W}, 15 \mathrm{~Hz}$, $100 \mathrm{~mJ}$, fluência do pulso de $124 \mathrm{~J} / \mathrm{cm}^{2}$ e com o tempo de utilização no interior do canal radicular proporcional à metade do comprimento dos canais (Figura 4.4). 


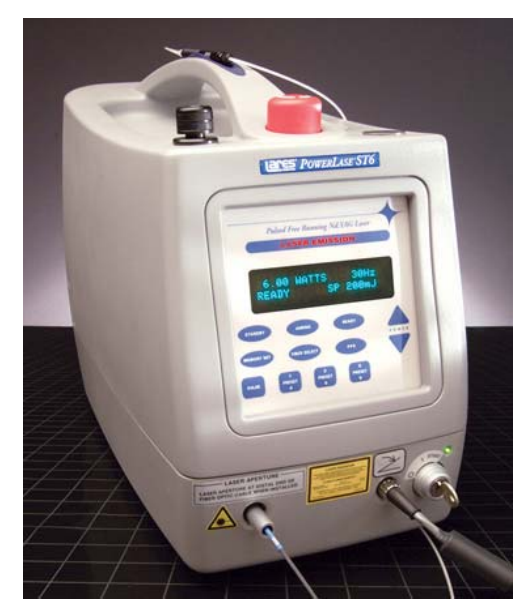

Figura 4.4 - Laser de Nd:YAG portátil

Os parâmetros de potência e energia foram previamente aferidos com auxílio de um monitor de potência e energia Nova (Ophir, Jerusalém, Israel. Projeto Fapesp 2005/57550-6) e um sensor (Ophir, Jerusalém, Israel. Projeto Fapesp 2005/575506). Para padronizar a distância segura do sensor e centralizar a fibra foi confeccionada uma peça rosqueada na sua extremidade. Esta distância foi calculada com os dados da abertura numérica da fibra $(0,22+/-0,02)$, parâmetros do sensor e os parâmetros do laser utilizado no experimento. O intervalo de relaxação térmica foi de 30 segundos entre cada aplicação, com um total de cinco aplicações em cada dente. Antes de iniciar a aplicação no dente seguinte a fibra foi limpa com lenço de papel umedecido em solução alcoólica e clivada quando necessário. Nova calibragem era realizada para atingir $100 \mathrm{~mJ}$ e $1,5 \mathrm{~W}$, bem como para iniciar a próxima série de aplicações (Figura 4.5).

Durante a técnica oscilatória, foi monitorada a aplicação com auxílio de um cronógrafo sonorizado, programado para um segundo. 

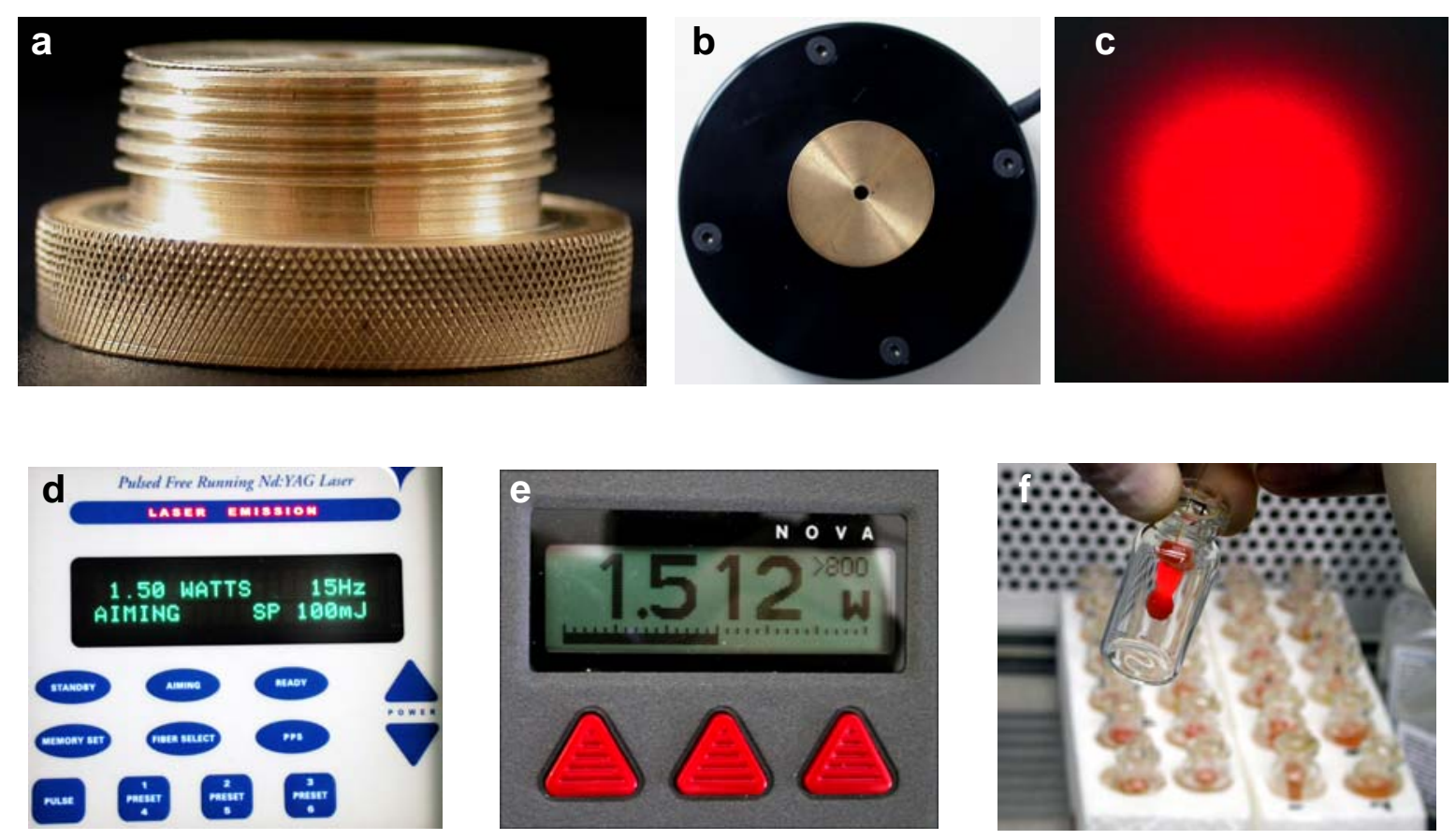

Figura 4.5 - a - Adaptador do sensor; b - sensor Ophir; c - avaliação da clivagem; d - parâmetros utilizados no laser; e - aferição da potência no monitor Nova Ophir; $f$ - aplicação do laser no dente, em ambiente de fluxo laminar

\subsection{Método de Avaliação}

Inicialmente foram realizadas diluições da endotoxina (teste $L A L$ ) resultando nas concentrações de $160 \mathrm{UE} / \mathrm{mL} ; 16 \mathrm{UE} / \mathrm{mL} ; 1,6 \mathrm{UE} / \mathrm{mL}$ e 0,16 UE/mL, 0,016 $\mathrm{UE} / \mathrm{mL} ; 0,0016 \mathrm{UE} / \mathrm{mL}$, que representam os padrões com os quais foi realizada a comparação da leitura das amostras.

As amostras foram analisadas pelo teste $\mathrm{LAL}$, turbidimétrico cinemático Pyrotell-T (Associates of Cape Code Incorporated, East Falmouth, MA, EUA). Alíquotas de $200 \mu \mathrm{L}$ da câmara inferior de cada um dos grupos experimentais e controle foram coletadas com auxílio de micropipetas, em seguida transferidas para a microplaca apirogênica Pyroplate Pyroclear (Associates of Cape Code 
Incorporated, East Falmouth, MA, EUA). Os testes para todas as amostras foram realizados em duplicata.

Conforme orientação do fabricante, a análise turbidimétrica cinemática foi realizada pela análise da curva de regressão linear em uma leitora de microplacas que possui sistema de medida de densidade óptica (absorbância). Foram coletados e dispensados na microplaca, separadamente, $200 \mu \mathrm{L}$ de cada amostra e $75 \mu \mathrm{L}$ de reagente em duplicata, imediatamente pré-incubados à temperatura de $37^{\circ} \mathrm{C}$ por 10 minutos, na própria leitora de absorbância Tecan Sunrise (Tecan Corp, Áustria, Europa). Posteriormente a este período de incubação, a microplaca foi removida e fechada e, em ambiente de fluxo laminar, foram retirados, com auxílio de um micropipetador multicanal (Eppendorf, Alemanha, Europa. Projeto Fapesp 2002/10462-7), $50 \mu \mathrm{L}$ de cada poço de reagente e adicionados aos poços contendo as amostras. A microplaca fechada foi imediatamente transportada para a leitora, onde, após remoção da tampa iniciou-se a leitura durante período de 90 minutos, com intervalos de 30 segundos, filtro de 405 nm, agitação inicial de nível baixo de 30 segundos e temperatura entre $36,5{ }^{\circ} \mathrm{C}$ e $37,5{ }^{\circ} \mathrm{C}$. Os dados obtidos na leitora foram armazenados no programa Magellan V5.0 ( Tecan Corp, Áustria, Europa ).

Os dados obtidos foram organizados por um programa desenvolvido pelo Instituto de Matemática e Estatística da Universidade de São Paulo. Destes dados, eram selecionados os três primeiros e os três últimos valores acima e abaixo de 20 milésimos de absorbância e os tempos respectivos, que, juntamente com os dados da curva padrão, foram inseridos em uma planilha Excel fornecida pelo laboratório do Associates of Cape Cod, Estados Unidos, com os cálculos programados para se obter as concentrações de endotoxinas de cada amostra.

As equações utilizadas na planilha foram: 
1 - Equação da reta

$\mathrm{Y}=\mathrm{a}+\mathrm{bX}$

$\mathrm{Y}=$ valor da variável dependente para um valor fornecido de uma variável independente $(X)$

$a=$ interseção em $Y$

$\mathrm{b}=$ inclinação da reta

$X=$ valor da variável independente $(X)$

2 - Equação da regressão linear

$X$ e $Y$ são as médias de $X$ e $Y$, respectivamente

$$
\text { Inclinação(b) }=\frac{\sum X Y-\bar{X} \sum Y}{\sum X^{2}-\bar{X} \sum \mathrm{X}}
$$

interseção em $\mathrm{Y}(\mathrm{a})=\bar{Y}-\mathrm{b} \bar{X}$

3 - cálculo de análise de correlação da concentração de endotoxina. Reação cinemática

$$
\mathrm{r}=\frac{\sum X Y-\bar{X} \sum Y}{\left.\sqrt{\left(\sum X^{2}\right.}-\bar{X} \sum X\right)\left(\sum Y^{2}-Y \sum Y\right)}
$$

Para calcular a concentração de endotoxina de amostras desconhecidas a partir de um tempo ajustado a equação da reta foi usada da seguinte forma:

$$
X=\frac{Y-a}{b}
$$

$X=\log _{10}$ da concentração de endotoxina.

$\mathrm{Y}=\log _{10}$ do começo do tempo ajustado em segundos. 
$a=$ interseção de $Y$ da curva padrão, calculada por análise de regressão linear.

b = inclinação da curva padrão calculada por análise de regressão linear.

Concentração de endotoxina $=\operatorname{antilog}_{10} \mathrm{X}$.

Posteriormente, os dados obtidos foram tabulados e submetidos à análise estatística.

\subsection{Análise Estatística}

Os dados de concentração da endotoxina (UE/ml) estão apresentados como média \pm o erro padrão de média de no mínimo de três amostras.

A normalidade das amostras foi analisada pelo teste de Lilliefors. Como os dados mostraram-se não aderentes a curva de normalidade, eles foram comparados pelo método não paramétrico de Kruskal-Wallis. Quando houve diferença, a análise foi complementada com o teste de Dunn. O nível de significância foi de $5 \%(p \leq 0,05)$. 


\section{RESULTADOS}

A concentração de endotoxina das amostras foi quantificada a cada 24 horas. Houve passagem de endotoxina das câmaras superiores para as inferiores através da dentina radicular de algumas amostras já nas primeiras 24 horas (Figura 5.1) Essa concentração aumentou significantemente $(p=0,0002)$ nas próximas 24 horas, quando se estabilizou. Em 72 horas a concentração da endotoxina nas câmaras inferiores foi similar àquela observada em 48 horas (Apêndices $A, E, F$ e G).

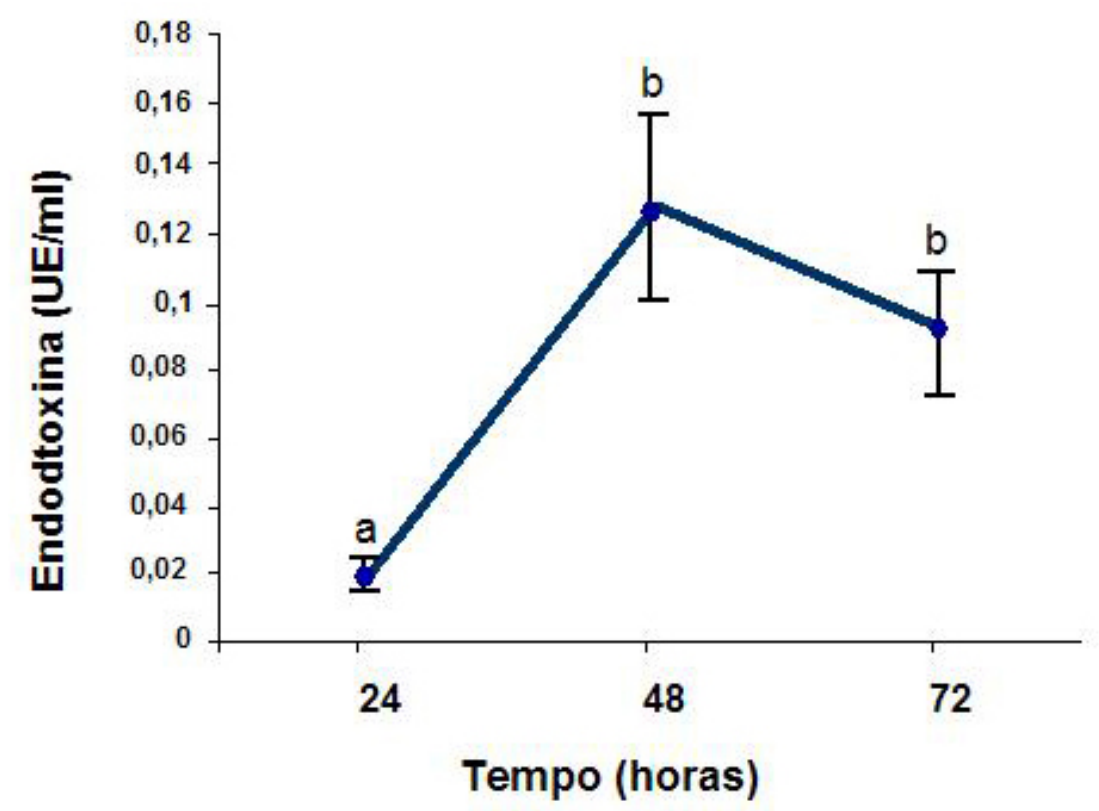

Figura 5.1 - Representação gráfica das concentrações de endotoxina (UE/ml) obtidas das amostras em tempos distintos. Letras diferentes indicam diferença estatisticamente significante $(p=0,0002)$

Este achado definiu o momento em que a concentração de endotoxina passou a ser quantificada nos experimentos com o laser de Nd:YAG. A partir deste experimento da cinemática de passagem de endotoxina através da dentina radicular 
para a câmara inferior, ficou determinado que, 72 horas após a inoculação de endotoxina na câmara superior das amostras de todos os grupos experimentais (controles, laser oscilatório e laser helicoidal), a concentração de endotoxina nas câmaras inferiores seria mensurada.

Para a validação dos grupos controles, as concentrações das endotoxinas nas câmaras inferiores dos grupos controle negativo e positivo foram comparadas. No grupo controle positivo, o canal radicular não era irradiado. No grupo controle negativo, o dente era totalmente impermeabilizado e o canal radicular não era irradiado (Figura 5.2). Houve diferença estatisticamente significante, mostrando que a concentração de endotoxina no controle negativo foi de 0,007 $\pm 0,0017 \mathrm{UE} / \mathrm{ml}$, enquanto no controle positivo foi de $0,045 \pm 0,0092 \mathrm{UE} / \mathrm{ml}(p=0,0495)$ (Apêndices $C$ e H).

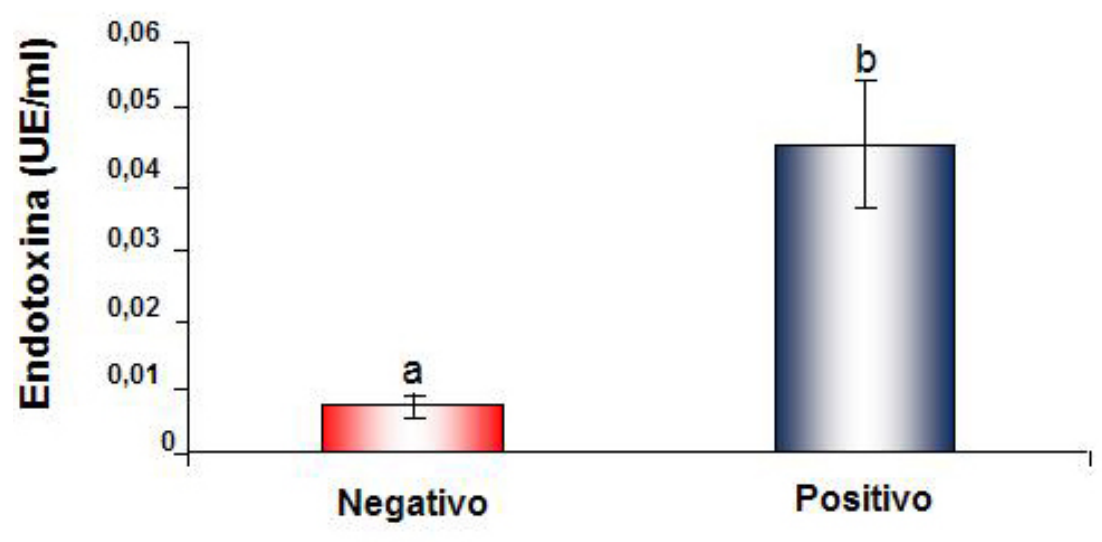

Controles

Figura 5.2 - Representação gráfica comparativa das concentrações de endotoxina nas câmaras inferiores das amostras dos grupos controle negativo com o positivo. Letras diferentes indicam diferença estatisticamente significante $(p=0,0495)$

A Figura 5.3 ilustra os resultados de concentração de endotoxina (UE/ml) dos grupos experimentais. Houve uma redução significativa $(p=0,0271)$ de 
concentração de endotoxina na câmara inferior das amostras entre o grupo controle positivo não irradiado e os grupos irradiados pelo laser de Nd:YAG pela técnica oscilatória e helicoidal. Adicionalmente, a concentração de endotoxina nos grupos irradiados foi similar $(p>0,05)$ (Apêndice B).

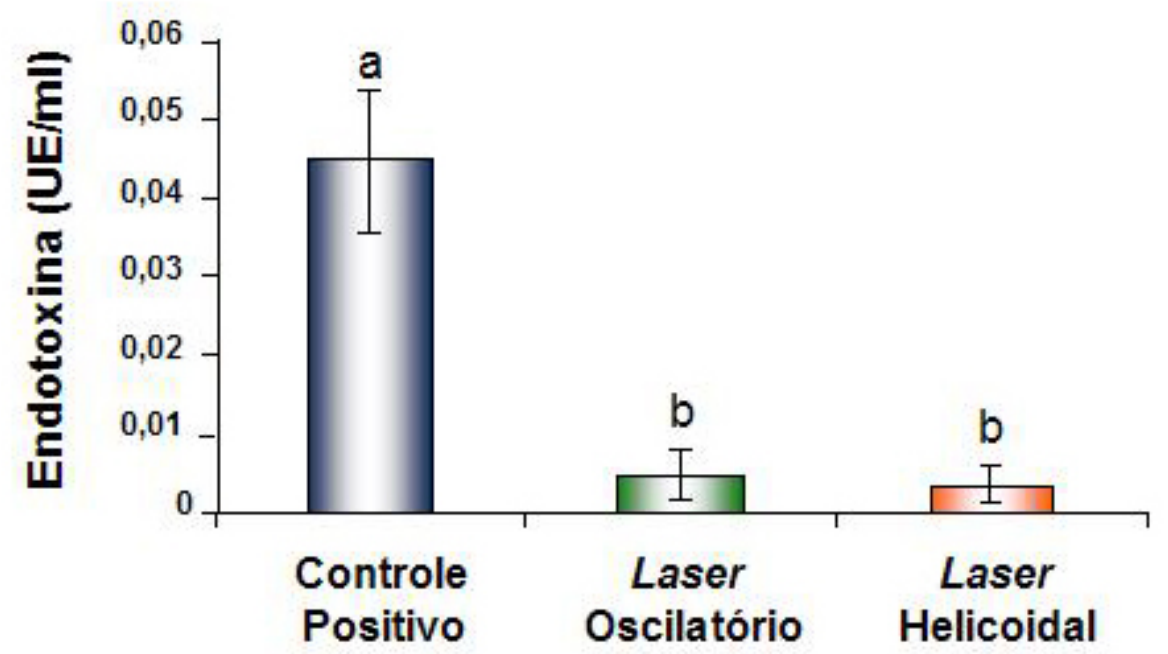

\section{Grupos Experimentais}

Figura 5.3 - Representação gráfica comparativa da concentração de endotoxina nas câmaras inferiores das amostras irradiadas pelo laser de $\mathrm{Nd}$ :YAG nas técnicas oscilatória e helicoidal com as do controle positivo. Letras diferentes indicam diferença estatisticamente significante $(p=0,0271)$

A comparação das concentrações de endotoxina nas câmaras inferiores das amostras dos grupos irradiados com o grupo controle negativo mostrou não haver diferenças significativas ( $p=0,2008)$ (Figura 5.4) (Apêndice D). 


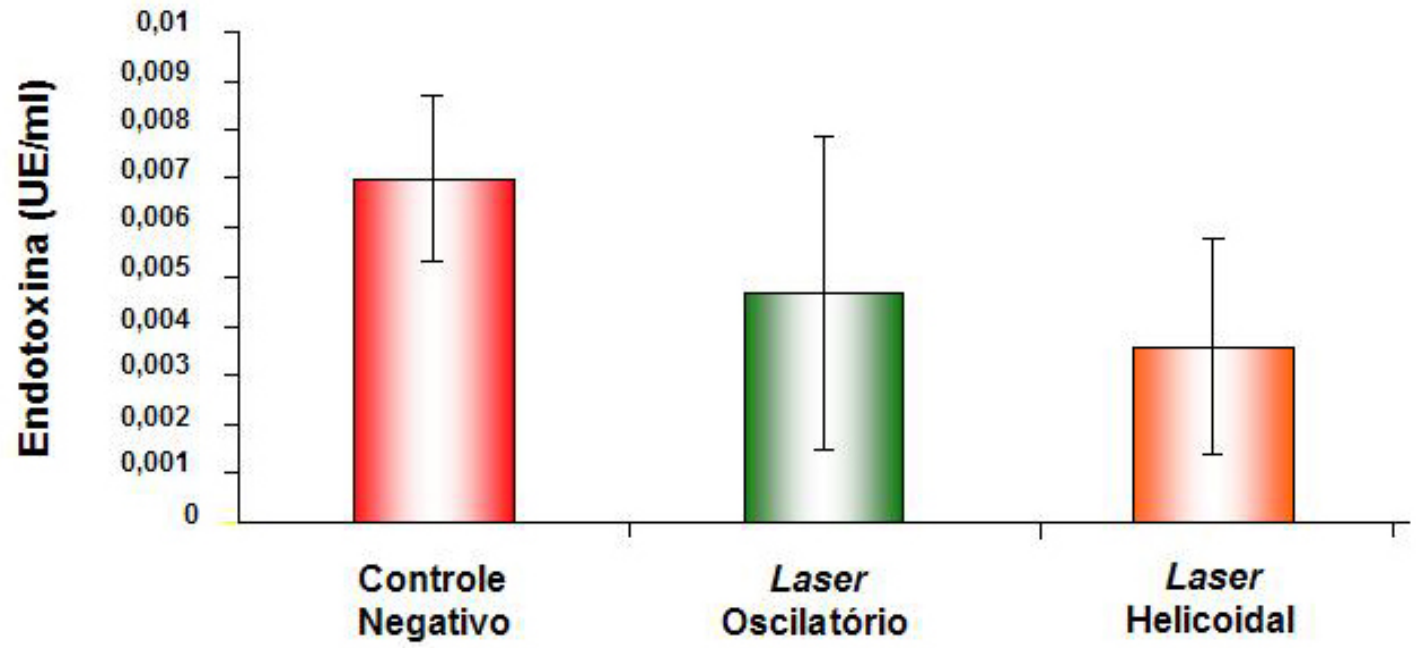

Grupos Experimentais

Figura 5.4 -Representação gráfica comparativa da concentração de endotoxina nas câmaras inferiores das amostras irradiadas pelo laser de $\mathrm{Nd}$ :YAG nas técnicas oscilatória e helicoidal com as do grupo controle negativo 


\section{DISCUSSÃO}

Bactérias Gram-negativas estão presentes em dentes com polpa necrosada e canais radiculares infectados. Essas bactérias possuem lipoproteínas e lipopolissacarídeos (LPS) na sua membrana externa. Os LPS, quando liberados por lise da célula ou durante o processo de divisão celular, são conhecidos como endotoxinas (RIETSCHEL; BRADE, 1992), que estão envolvidas na destruição tecidual e podem estimular a produção de bradicinina, que é um importante mediador da dor (FARBER; SELTZER, 1988). Portanto, durante tratamento endodôntico, que visa destruir as bactérias presentes no canal radicular, há liberação de endotoxinas que podem ocasionar uma série de reações locais e sistêmicas, levando, em casos extremos, até a morte do hospedeiro (MADIGAN; MARTINKO; PARKER, 2006). Daí a importância de se buscar uma forma que propicie a inativação da endotoxina durante o tratamento endodôntico.

Vários fármacos, destacando-se o hidróxido de cálcio, têm sido utilizados no para promover a desinfecção do sistema de canais radiculares e a inativação das endotoxinas. Porém, apesar dos bons resultados obtidos em pesquisas que utilizaram o hidróxido de cálcio como medicação intracanal, a presença de pó de dentina decorrente da instrumentação endodôntica cria um efeito inibitório sobre a ação dessa substância (HAAPASALO et al., 2000). Assim, nos interessamos em buscar um tratamento complementar à terapia endodôntica que fosse capaz de promover a inativação da endotoxina presente no sistema de canais radiculares.

Um dos procedimentos utilizados com sucesso na complementação do tratamento endodôntico tem sido a irradiação com laser. Os lasers têm sido utilizados em Endodontia desde a década de 70, quando Adrian (1977) avaliou os 
efeitos do laser de Nd:YAG na polpa de macacos rhesus (AOKI et al., 2000). Mais tarde, com o desenvolvimento de um sistema de entrega do laser de Nd:YAG baseado em fibras ópticas que trabalhavam em contato direto, foi possível se obter corte de tecido mole, redução bacteriana e selamento de túbulos dentinários com potências menores (COLUZZI, 2000). Clinicamente, nota-se que o laser de Nd:YAG, quando utilizado no tratamento endodôntico de dentes com presença de lesão apical, sem utilização de medicação intracanal, onde há presença de bactérias Gram-negativas, proporciona um elevado índice de sucesso na reparação de lesões periapicais (GUTKNECHT et al., 1996a).

Baseado no exposto, esta pesquisa in vitro objetivou testar se a irradiação com laser de Nd:YAG seria também capaz de promover a inativação de endotoxina presente na dentina de raízes dentárias humanas. Assim, foram utilizadas raízes dentárias de humanos, nas quais a endotoxina foi inoculada no canal radicular em quantidade suficiente para que houvesse sua passagem para a porção externa da raiz onde ela era coletada e quantificada. Essas raízes impregnadas pela endotoxina eram então submetidas ao tratamento endodôntico convencional seguido ou não pela irradiação com laser de Nd:YAG em duas cinemáticas. A quantificação da endotoxina após as irradiações mostrou, nas condições experimentais aqui empregadas, que foi possível observar a total inativação da endotoxina após a terapia com laser de Nd:YAG, independentemente da cinemática aplicada.

Um ponto de importância neste tipo de pesquisa diz respeito à preparação das amostras e dos materiais a serem utilizados nos experimentos, para evitar qualquer tipo de interferência nas leituras para quantificação da endotoxina, tanto antes como depois da instituição do tratamento endodôntico.

A facilidade de contaminação com LPS e o padrão de exigência na redução da sua concentração em materiais distintos, demandam rigor no controle prévio, 
durante e posterior à sua presença. É relevante também o fato de determinados materiais possuírem característica de absorção, alterando a interpretação das leituras de concentração. Por essas razões, todos os materiais utilizados foram escolhidos e preparados de forma adequada para evitar interferências na detecção da endotoxina (NOVITSKY; SCHMIDT-GENGENBACH; REMILLARD, 1986; ROSLANSKY; DAWSON; NOVITSKY, 1991; TROPE; CHOW; NISSAN, 1995; TWOHY; DURAN; PEELER, 1986).

Os métodos de esterilização foram avaliados antecipadamente para proporcionar a maior redução de endotoxina possível e sem interferir nas características dos materiais (CSAKO et al.,1983; LUDWIG; AVIS, 1990; NAKATA, 1993; NAKATA, 1994; WHITE et al., 1994). Após um período de incubação, confirmando a passagem das endotoxinas inoculadas no canal radicular através da dentina e do cemento radicular, a irradiação com laser de Nd:YAG foi realizada com movimentos oscilatório ou helicoidal para posterior leitura e comparação com os grupos controle não irradiados.

Os baixos valores de concentrações de endotoxina na última leitura nas amostras irradiadas justificaram a preocupação da utilização de materiais que não provocassem absorção dessas, o que ocasionaria inviabilidade do experimento ou interpretação equivocada.

O modelo experimental que obteve duas câmaras independentes separadas somente por dentina radicular, graças à presença de cera utilidade para impermeabilização cervical e apical das raízes dentárias foi baseado no estudo de Trope, Chow e Nissan (1995), que obtiveram melhores resultados de isolamento de endotoxinas utilizando esse material em comparação ao cianoacrilato e ao esmalte de unha. 
Vários estudos confirmam a adsorção de endotoxinas com a utilização do plástico à base de polipropileno (NOVITSKY; SCHMIDT-GENGENBACH; REMILLARD, 1986; ROSLANSKY; DAWSON; NOVITSKY, 1991; TWOHY; DURAN; PEELER, 1986). Por essa razão, os plásticos à base de poliestireno foram utilizados. Segundo Roslansky; Dawson e Novitsky (1991) para facilitar o processo de remoção dos plásticos dos seus moldes, alguns reagentes químicos são utilizados podendo interferir nos testes de endotoxina, assim como, se os plásticos não forem manuseados em condições apropriadas, também poderá ocorrer contaminação. Daí a importância da origem do produto e atestado de ausência de pirogênio.

Os vidros com menor adsorção de endotoxinas são os vidros de borosilicato e os vidros de chumbo (NOVITSKY; SCHMIDT-GENGENBACH; REMILLARD, 1986; ROSLANSKY; DAWSON; NOVITSKY, 1991). Neste experimento, utilizamos tubos de vidro de borosilicato apirogênicos e, para efeito do padronização, foram confeccionados vidros de mesmo material para a utilização na câmara inferior.

A dose utilizada na irradiação de materiais do experimento, 30 kGy, foi determinada após estudo piloto prévio da tolerância máxima da cera utilidade, sem causar alterações exageradas de sua coloração e estrutura. Essa dose está em acordo com estudo de CSAKO et al. (1983) que obtiveram redução significativa de endotoxinas somente após radiações excedentes a 25 kGy. Segundo os mesmos autores, há um decréscimo exponencial da atividade do LAL (Lisado de Amebócito Limulus) nos lipopolissacarídeos após o tratamento com a radiação ionizante, que foi totalmente anulado após utilização de 30 kGy.

White et al. (1994), em um estudo de esterilização de dentes, compararam a irradiação gama com o óxido de etileno, calor e autoclave. Utilizaram dose de 
irradiação de até 173 kGy e, diferentemente dos demais métodos, não houve alteração da permeabilidade e das propriedades ópticas da dentina.

A utilização de água milliQ na irrigação final após o utilização de solução de hipoclorito de sódio a $2,5 \%$, seguida de solução de EDTA a $17 \%$, foi devido à preocupação em se remover íons quelantes residuais que poderiam realizar ligações químicas com as endotoxinas interferindo no teste turbidimétrico utilizado.

A água milliQ, assim como as águas obtidas pelos processos de destilação, osmose reversa, ultrafiltração e nanofiltração, possui capacidade de remoção completa ou próxima do total de endotoxinas. Optamos pela primeira para realizar a irrigação final devido às suas características, pois para ser produzida, ela é destilada e deionizada. Na destilação, a água em estado líquido é levada ao estado gasoso (vapor) e condensada novamente ao estado líquido. Devido à diferença, de peso molecular, há uma redução de endotoxinas. Na deionização, ocorre uma troca de íons para obter água reagente de alta resistividade. Nesse processo, há uma redução de íons presentes que poderiam interferir na leitura das endotoxinas.

Para o preparo das amostras de controle positivo e experimentais, utilizamos uma fatia de dentina na região apical para que as amostras irradiadas não deslocassem a cera utilidade comprometendo a impermeabilização. A colagem deste tampão foi realizada com resina resistente a altas doses de radiação gama.

A ausência de endotoxinas 72 horas após a adição de água apirogênica nas câmaras superior e inferior em ambiente de fluxo laminar após o processo de esterilização confirmou a eficiência da metodologia utilizada e propiciou maior confiabilidade para a seqüência do experimento. Trope; Chow e Nissan (1995) já haviam utilizado esse procedimento de checagem de esterilização, porém antecedido de um processo de esterilização distinto. 
Neste experimento, foi utilizado a endotoxina pura de E. coli, uma vez que todas as endotoxinas produzem os mesmos sinais e sintomas, independente da espécie de microrganismo, embora não na mesma intensidade (MADIGAN; MARTINKO; PARKER, 2006).

A escolha do método turbidimétrico cinemático Pyrotell-T de avaliação da concentração de endotoxinas deveu-se à sua maior sensibilidade $(0,001 \mathrm{UE} / \mathrm{ml})$, viabilizando a diferenciação dos baixos valores obtidos na metodologia utilizada. Outro método disponível é o gel clot $(0,03 ; 0,06 ; 0,125 ; 0,25 \mathrm{UE} / \mathrm{ml})$, mas possui baixa sensibilidade e é considerado apenas semiquantitativo porque possui valores predeterminados.

Diferentemente do método cromogênico ou colorimétrico $(0,005 \mathrm{UE} / \mathrm{ml})$, que disponibiliza as opções cinemática e end point, no qual esta última avalia a concentração de endotoxina somente no final do experimento, o método turbidimétrico possui somente a opção cinemática, que possibilita o acompanhamento de toda a curva de concentração, fato importante, pois nem sempre o valor final no tempo predeterminado do experimento é o valor de maior concentração.

Outros lasers que utilizem fibra óptica como sistema de entrega, como os lasers de diodo de 810 nm, diodo de 980 nm, Er:YAG, Er,Cr:YSGG ou KTP também poderiam ter sido utilizados na tentativa de degradar a endotoxina. Porém, a opção pelo laser de Nd:YAG foi por causa da existência de um número maior de estudos realizados na utilização intracanal deste laser com parâmetros de utilização já consagrados, e de eficácia na redução microbiana (BERGMANS et al., 2006; BERKITEN; BERKITEN; OKAR, 2000; GUTKNECHT et al., 1996a; GUTKNECHT et al., 1996b; KLINKE; KLIMM; GUTKNECHT, 1997; MORITZ et al., 1999; MORITZ et 
al., 2000; SCHOOP et al., 2004), sem causar efeitos térmicos indesejáveis (ANIC; TACHIBANA; MASUMOTO, 1996; ARCHILLA, 2001; BEHRENS et al., 1993; GUTKNECHT et al., 1996b; KHAN et al.,1997; LAN, 1999; RAMSKOLD; FONG; STROMBERG, 1997).

A irradiação do laser de Nd:YAG promove a fusão e a ressolidificação da dentina, fechando os túbulos, reduzindo a permeabilidade dentinária e promovendo, ainda, o aumento da microdureza da dentina. Suas características tornam este laser capaz de produzir vaporização e remover magma dentinário existente no interior de canais radiculares (BEHRENS et al., 1993; ANIC; TACHIBANA; MASUMOTO, 1996).

A desinfecção proporcionada pela terapia laser constitui fator primordial de seu emprego, por causa da sua maior profundidade de penetração nos túbulos dentinários, comparada às soluções irrigantes e medicamentos intracanal, possibilitando combater bactérias resistentes ao tratamento endodôntico convencional e, conseqüentemente minimizando as reações pós-operatórias (ØRSTAVIK; FORD, 1998; HAAPASALO et al., 2000).

A descontaminação dos canais radiculares ocorre basicamente pela vaporização de material orgânico ou debris remanescentes, diminuindo a possibilidade dos microrganismos se proliferarem. Nesse caso, o material a ser removido precisa absorver fortemente o comprimento de onda a ser irradiado. A ação térmica também propicia a descontaminação por causa da penetração além da região superficial da parede da dentina, interagindo no interior dos túbulos dentinários.

O experimento realizado analisou a atuação do laser em endotoxinas bacterianas em virtude do papel que desempenham localmente e à distância (DAHLEN; MAGNUSSON; MOLLER, 1981; DWYER; TORABINEJAD, 1981; 
HORIBA et al.,1990; HORIBA et al., 1991; HORIBA et al.,1992; HOSOYA; MATSUSHIMA, 1997; JACINTO et al., 2005; JIANG et al., 2002; KHABBAZ; ANASTASIADIS; SYKARAS, 2000; KHABBAZ; ANASTASIADIS; SYKARAS, 2001; MURRAY; SAUNDERS, 2000; NISSAN et al.,1995; OLIVEIRA et al., 2005a; PITTS; WILLIAMS; MORTON, 1982; RAISZ et al., 1981; SCHEIN; SCHILDER, 1975; SCHONFELD et al., 1982; WESSELINK; THODEN VAN VELZEN; MAKKES, 1978; YAMASAKI et al., 1992;).

Vários estudos demonstram que as soluções irrigadoras mais utilizadas, clorexidina e hipoclorito de sódio, em diversas concentrações, não inativam o LPS (BERUTTI; MARINI; ANGERETTI,1997; BUCK et al., 2001; BUTTLER; CRAWFORD, 1982; GRENIER; BERTRAND; MAYRAND,1995; LAGE MARQUES; ANTONIAZZI, 2000; OLIVEIRA et al., 2007; SILVA et al., 2002; SILVA et al., 2004; TANOMARU et al., 2003), entretanto, resultados positivos foram encontrados na utilização do antibiótico polymyxin $B$ e do hidróxido de cálcio na medicação intracanal (BUCK et al. 2001; OLIVEIRA et al., 2005b; OLIVEIRA et al. 2007; SAFAVI; NICHOLS 1993; SAFAVI; NICHOLS 1994).

O hidróxido de cálcio, até o presente momento, é o único medicamento utilizado intracanal que também demonstra resultados na inativação das endotoxinas à distância (JIANG et al. 2003; OLIVEIRA et al. 2005b; OLIVEIRA et al. 2007; SILVA et al., 2002; TANOMARU et al., 2003). Isso se deve à sua característica alcalina, que provoca hidrólise do lipídio A convertendo-o em ácidos graxos e açúcares atóxicos.

A ineficácia dos irrigantes intracanal e as limitações dos medicamentos utilizados na redução ou inativação de LPS, durante o tratamento endodôntico, despertam interesse na avaliação da atuação do laser à distância nas endotoxinas presentes na dentina radicular. 
O aumento significativo de endotoxina na câmara inferior, 48 horas após a inoculação de $16 \mathrm{UE} / \mathrm{ml}$ de endotoxina na câmara superior, que se estabilizou após 72 horas, determinou o momento adequado da irradiação. A análise do teor de endotoxina na câmara inferior a cada 24 horas mostrou resultados similares aos observados por Oliveira et al. (2005a), que demonstraram difusão de endotoxina através dos túbulos dentinários e do cemento, atingindo a região externa na raiz após 24 horas. Os mesmos autores obtiveram uma estabilização da concentração em um período de até sete dias. Outros autores como Nissan et al. (1995) também estudaram a habilidade da difusão das endotoxinas através da dentina em direção apical utilizando o teste de LAL e obtiveram a passagem de $0,5 \mathrm{~mm}$ em um período que variou de 15 minutos a 4,5 horas.

Ainda com o objetivo de validar a metodologia a primeira comparação feita foi entre a concentração de endotoxina na câmara inferior das amostras do grupo controle positivo, em que houve a inoculação da endotoxina sem a realização de irradiação com o laser de Nd:YAG contra o negativo, em que houve a inoculação, porém as raízes dentárias estavam totalmente impermeabilizadas com cera utilidade. Como esperado, a concentração de endotoxina obtida das amostras de controle positivo foram significativamente maiores que as do controle negativo.

Uma vez validada a metodologia, foram realizadas as irradiações nas duas cinemáticas propostas (oscilatória e helicoidal). A análise de endotoxina presente nas câmaras inferiores das amostras irradiadas mostrou concentrações mínimas que foram semelhantes entre si e significativamente menores que aquelas das amostras do controle positivo não irradiadas. Surpreendentemente, essas concentrações de endotoxina dos grupos irradiados foram similares àquelas do grupo controle negativo. Esses dados apontam para o sucesso da terapia com o laser de Nd:YAG 
na degradação das endotoxinas dentro da dentina radicular. Esse resultado pode ter sido obtido ou pela inativação da endotoxina dentro da dentina, impossibilitando-a de difundir-se além do cemento em direção da água da câmara inferior, ou mesmo pela ação mais à distância ainda da irradiação, degradando não só a endotoxina dentro da dentina radicular, mas também aquela contida na água da câmara inferior. Se a última hipótese for correta, poderia se esperar que in vivo a irradiação com o laser de Nd:YAG não só esterilizasse a raiz dentária, mas também o tecido periapical.

A diferença dos grupos experimentais com o grupo controle positivo era esperada pelo fato de estudos anteriores com o laser de $\mathrm{Nd}$ :YAG demonstrarem eficiência de redução bacteriana à distância (BERGMANS et al., 2006; BERKITEN; BERKITEN; OKAR, 2000; KLINKE; KLIMM; GUTKNECHT, 1997; MORITZ et al., 2000; SCHOOP et al., 2004).

As concentrações similares de endotoxina nos dois grupos irradiados surpreendeu pelo fato da irradiação do laser de Nd:YAG promover a fusão e a ressolidificação da dentina a uma temperatura próxima a $1200{ }^{\circ} \mathrm{C}$ na dentina adjacente a irradiação e em estudo anterior de Archilla (2001) observou-se uma melhor distribuição do calor no terço médio e apical durante a irradiação, utilizando a cinemática oscilatória em comparação com o que ocorreu com a técnica helicoidal.

Diferentemente o estudo de Schoop et al. (2004) concluiu que não ocorreu correlação entre o aumento de temperatura e a eficiência bactericida entre os lasers de Nd:YAG, diodo de 810 nm, Er:YAG e Er,Cr:YSGG.

No experimento realizado, também não ocorreu diferença significativa entre os grupos experimentais e o controle negativo.

Segundo Farber e Seltzer (1988), a presença de endotoxinas pode estimular a produção de bradicinina, que é um importante mediador da dor. Outros estudos 
associam áreas periapicais radiolucentes à presença de endotoxinas (HORIBA et al., 1991; JACINTO et al., 2005; KHABBAZ; ANASTASIADIS; SYKARAS, 2000; KHABBAZ; ANASTASIADIS; SYKARAS, 2001; SCHEIN; SCHILDER, 1975; SCHONFELD et al., 1982; YAMASAKI et al., 1992).

Os resultados obtidos poderiam justificar as observações clínicas de um melhor pós-operatório e eficiência na reparação tecidual no uso do laser de Nd:YAG intracanal. Dadas as características nocivas das endotoxinas e o poder do laser de Nd:YAG em inativar tal substância, seriam esperados resultados clínicos melhores com a utilização dessa irradiação, complementando o tratamento endodôntico convencional.

Baseado no estudo de Schoop et al. (2004) que obteve redução significativa de Escherichia coli, à distância, no uso dos lasers de diodo de 810 nm, Er:YAG e Er,Cr:YSGG, é provável que a utilização destes comprimentos de onda, assim como os lasers de diodo de $980 \mathrm{~nm}$ e o KTP, também obtenham resultados satisfatórios na redução de endotoxinas.

O resultado do experimento assegura a utilização clínica do laser de Nd:YAG no tratamento endodôntico onde há presença de bactérias Gram-negativas dados os benefícios da inativação imediata das endotoxinas.

Novos estudos são necessários para confirmar a metodologia utilizada com o hidróxido de cálcio e outros comprimentos de onda. 


\section{CONCLUSÃO}

Considerando as condições de desenvolvimento deste experimento, acreditamos ser lícito concluir que:

A irradiação com o laser de Nd:YAG inativa as endotoxinas presentes na dentina radicular independentemente da cinemática utilizada, seja helicoidal ou oscilatória. 


\section{REFERÊNCIAS ${ }^{1}$}

Adrian JC. Pulp effects of neodymium laser. A preliminary report Oral Surg Oral Med Oral Pathol. 1977;44(2):301-5.

Anic I, Tachibana H, Masumoto K, Qi P. Permeability, morphologic and temperature changes of canal dentine walls induced by Nd: YAG, CO2 and argon lasers. Int Endod J. 1996;29(1):13-22.

Aoki A, Sasaki KM, Watanabe H, Ishikawa I. Lasers in nonsurgical periodontal therapy. Periodontol 2000. 2004;36:59-97.

Archilla JRF. Análise térmica de diferentes técnicas de utilização do laser de $\mathrm{Nd}$ :YAG após o preparo químico-cirúrgico de dentes unirradiculares [Dissertação de Mestrado]. São Paulo: Instituto de Pesquisas Energéticas e Nucleares / Faculdade de Odontologia da Universidade de São Paulo; 2001.

Bahcall J, Howard P, Miserendino L, Walia H. Preliminary investigation of the histological effects of laser endodontic treatment on the periradicular tissues in dogs. J. Endod 1992;18,(2):47-51.

Behrens VG, Gutknecht N, Renziehausen R, Lampert F. Die transmission und absorption der temperatur und energie des Nd:YAG-lasers im dentin. ZWR. 1993;102( 9):629-34.

Bergenholtz G, Crawford JJ. Endodontic microbiology. In: WALTON RE, TORABINEJAD M, ed. Principles and practice of endodontics. 1a ed. Philadelphia: W.B. Saunders Co; 1989.p.267-82.

Bergmans L, Moisiadis P, Teughels W, Van Meerbeek B, Quirynen M, Lambrechts $P$. Bactericidal effect of Nd:YAG laser irradiation on some endodontic pathogens ex vivo. Int Endod J 2006 Jul;39(7):547-57.

Berkiten M, Berkiten R, Okar I. Comparative evaluation of antibacterial effects of $\mathrm{Nd}$ :YAG laser irradiation in root canals and dentinal tubules. J Endod 2000 May;26(5):268-70.

\footnotetext{
${ }^{1}$ De acordo com Estilo Vancouver. Abreviatura de periódicos segundo base de dados MEDLINE
} 
Berutti E, Marini R, Angeretti A. Penetration ability of different irrigants into dentinal tubules. J Endod. 1997;23(12):725-7.

Bhaskar SN. Histologia e embriologia oral de orban. $8^{\text {a. }}$ ed. São Paulo: Artes Médicas; 1978.

Bier O. Bacteriologia e imunologia. $22^{a}$ ed. São Paulo: Melhoramentos; 1982.

Buck RA, Cai J, Eleazer PD, Staat RH, Hurst HE. Detoxification of endotoxin by endodontic irrigants and calcium hydroxide. J Endod 2001;27(5):325-7.

Buttler TK, Crawford JJ. The detoxifying effect of varying concentrations of sodium hypochlorite on endotoxins. J Endod 1982;8(2):59-66.

Coluzzi DJ. An overview of laser wavelengths used in dentistry. Dent Clin North Am 2000;44(4):753-65.

Csako G, Elin RJ, Hochstein HD, Tsai C. Physical and biological properties of U.S. standard endotoxin EC after exposure to ionizing radiation. Infect Immun 1983;41(1):190-96.

Dahlen G, Magnusson BC, Moller A. Histological and histochemical study of the influence of lipopolysaccharide extracted from Fusobacterium nucleatum on the periapical tissues in the monkey Macaca fascicularis. Arch Oral Biol 1981;26(7):591-8.

Debelian GJ, Olsen I, Tronstad L. Bacteremia in conjunction with endodontic therapy. Endod Dent Traumatol 1995;11(3):142-9.

Dwyer TG, Torabinejad M. Radiographic and histologic evaluation of the effect of endotoxin on the periapical tissues of the cat. J Endod 1981;7(1):31-5.

El Karim I, Kennedy J, Hussey D. The antimicrobial effects of root canal irrigation and medication. Oral Surg Oral Med Oral Pathol Oral Radiol Endod 2007;103(4):560-9.

Eriksson AR, Albrektsson T. Temperature threshold levels for heat-induced bone tissue injury: a vital-microscopic study in the rabbit. J Prosthet Dent 1983;50(1):101-7. 
Eriksson RA, Albrektsson T. The effect of heat on bone regeneration: an experimental study in the rabbit using the bone growth chamber. J Oral Maxillofac Surg 1984;42(11):705-11.

Estrela C, Pimenta FC, Ito IY, Bammann LL. Antimicrobial evaluation of calcium hydroxide in infected dentinal tubules. J Endod 1999;25(6):416-8.

Evans ME, Feola DJ, Rapp RP. Polymyxin B sulfate and colistin: old antibiotics for emerging multiresistant gram-negative bacteria. Ann Pharmacother 1999;33(9):960-7.

Fabricius L, Dahlën G, Öhman AE, Möller AJ. Predominant indigenous oral bacteria isolated from infected root canals after varied times of closure. Scand $\mathrm{J}$ Dent Res 1982;90(2):134-44.

Farber PA, Seltzer S. Endodontic microbiology. I. Etiology. J Endod 1988;14(7):363-71.

Gomes BP, Jacinto RC, Pinheiro ET, Sousa El, Zaia AA, Ferraz CC, et al. Molecular analysis of Filifactor alocis, Tannerella forsythia, and treponema denticola associated with primary endodontic infections and failed endodontic treatment. J Endod 2006;32(10):937-40.

Gomes BP, Lilley JD, Drucker DB. Clinical significance of dental root canal microflora. J Dent 1996;24(1-2):47-55.

Gomes BP, Pinheiro ET, Gade-Neto CR, Sousa El, Ferraz CC, Zaia AA, Teixeira $\mathrm{FB}$, et al. Microbiological examination of infected dental root canals. Oral Microbiol Immunol 2004;19(2):71-6.

Grenier D, Bertrand J, Mayrand D Porphyromonas gingivalis outer membrane vesicles promote bacterial resistance to chlorhexidine. Oral Microbiol Immunol 1995;10(5):319-20.

Gutknecht N, Kaiser F, Hassan A, Lampert F. Long-term clinical evaluation of endodontically treated teeth by Nd:YAG lasers. J Clin Laser Med Surg 1996a;14(1):7-11.

Gutknecht N, Moritz A, Conrads G, Sievert T, Lampert F. Bactericidal effect of the Nd:YAG laser in in vitro root canals. J Clin Laser Med Surg 1996b;14(2):77-80. 
Haapasalo HK, Siren EK, Waltimo TM, Orstavik D, Haapasalo MP. Inactivation of local root canal medicaments by dentine: an in vitro study. Int Endod J 2000;33(2):126-31.

Hashioka K, Yamasaki M, Nakane A, Horiba N, Nakamura H. The relationship between clinical symptoms and anaerobic bacteria from infected root canals. J Endod 1992;18(11):558-61.

Horiba N, Maekawa Y, Abe Y, Ito M, Matsumoto T, Nakamura H. Correlations between endotoxin and clinical symptoms or radiolucent areas in infected root canals. Oral Surg Oral Med Oral Pathol 1991;71(4):492-5.

Horiba N, Maekawa Y, Matsumoto T, Nakamura H. A study of the distribution of endotoxin in the dentinal wall of infected root canals. J Endod 1990;16(7):331-4.

Horiba N, Maekawa Y, Yamauchi Y, Ito M, Matsumoto T, Nakamura H. Complement activation by lipopolysaccharides purified from gram-negative bacteria isolated from infected root canals. Oral Surg Oral Med Oral Pathol 1992;74(5):648-51.

Hosoya S, Matsushima K. Stimulation of interleukin-1 beta production of human dental pulp cells by Porphyromonas endodontalis lipopolysaccharide. J Endod 1997;23(1):39-42.

Jacinto RC, Gomes BP, Ferraz CC, Zaia AA, J Filho F. Microbiological analysis of infected root canals from symptomatic and asymptomatic teeth with periapical periodontitis and the antimicrobial susceptibility of some isolated anaerobic bactéria. Oral Microbiol Immunol 2003;18(5):285-92.

Jacinto RC, Gomes BP, Shah HN, Ferraz CC, Zaia AA, Souza-Filho FJ. Quantification of endotoxins in necrotic root canals from symptomatic and asymptomatic teeth. J Med Microbiol 2005;54(Pt 8):777-83.

Jiang J, Zuo J, Chen SH, Holliday LS. Calcium hydroxide reduces lipopolysaccharide-stimulated osteoclast formation. Oral Surg Oral Med Oral Pathol Oral Radiol Endod 2003;95(3):348-54.

Jiang Y, Mehta CK, Hsu TY, Alsulaimani FF. Bacteria induce osteoclastogenesis via an osteoblast-independent pathway. Infect Immun 2002;70(6):3143-8. 
Khabbaz MG, Anastasiadis PL, Sykaras SN. Determination of endotoxins in caries: association with pulpal pain. Int Endod J 2000;33(2):132-7.

Khabbaz MG, Anastasiadis PL, Sykaras SN. Determination of endotoxins in the vital pulp of human carious teeth: association with pulpal pain. Oral Surg Oral Med Oral Pathol Oral Radiol Endod 2001;91(5):587-93.

Khan MA, Khan MF, Khan MW, Wakabayashi H, Matsumoto K. Effect of laser treatment on the root canal of human teeth. Endod Dent Traumatol 1997;13(3):139-45.

Klinke T, Klimm W, Gutknecht N. Antibacterial effects of Nd:YAG laser irradiation within root canal dentin. J Clin Laser Med Surg 1997 Feb;15(1):29-31.

Lage Marques JL, Antoniazzi JH. Quando a medicação intracanal é fundamental para o sucesso da terapia endodôntica In: Atualização na clínica odontológica. São Paulo: Artes Médicas, 2000. v. 1. cap. 3,. p. 59-89.

Lan WH. Temperature elevation on the root surface during Nd:YAG laser irradiation in the root canal. J Endod 1999;25(3):155-6.

Leonardo MR, Filho T, Silva LAB, Filho N, Bonifácio KC, Ito IY. In vivo antimicrobial activity of $2 \%$ chlorhexidine used as a root canal irrigating solution. $\mathrm{J}$ Endod 1999;25(3):167-171.

Lin L, Langeland K. Light and electron microscopic study of teeth with carious pulp exposures. Oral Surg Oral Med Oral Pathol 1981;51(3):292-316.

Ludwig JD, Avis KE. Dry heat inactivation of endotoxin on the surface of glass. J Parenter Sci Technol 1990;44(1):4-12.

Madigan MT, Martinko JM, Parker J. Brock biology of microorganisms. 11a ed. Upper Saddle River: Prentice Hall; 2006.

Moritz A, Jakolitsch S, Goharkhay K, Schoop U, Kluger W, Mallinger R, et al. Morphologic changes correlating to different sensitivities of Escherichia coli and enterococcus faecalis to Nd:YAG laser irradiation through dentin. Lasers Surg Med. 2000;26(3):250-61. 
Moritz A, Schoop U, Goharkhay K, Jakolitsch S, Kluger W, Wernisch J, et al. The bactericidal effect of Nd:YAG, Ho:YAG, and Er:YAG laser irradiation in the root canal: an in vitro comparison. J Clin Laser Med Surg. 1999;17(4):161-4.

Murray CA, Saunders WP. Root canal treatment and general health: a review of the literature. Int Endod J 2000;33(1):1-18.

Nagayoshi M, Kitamura C, Fukuizumi T, Nishihara T, Terashita M. Antimicrobial effect of ozonated water on bacteria invading dentinal tubules. J Endod 2004 Nov;30(11):778-81.

Nakata T. Destruction of challenged endotoxin in a dry heat oven. J Parenter Sci Technol 1994;48(2):59-63.

Nakata T. Destruction of typical endotoxins by dry heat as determined using LAL assay and pyrogen assay. J Parenter Sci Technol 1993;47(5):258-64.

Nissan R, Segal H, Pashley D, Stevens R, Trowbridge H. Ability of bacterial endotoxin to diffuse through human dentin. J Endod 1995;21(2):62-4.

Novitsky TJ, Schmidt-Gengenbach J, Remillard JF. Factors affecting recovery of endotoxin adsorbed to container surfaces. J Parenter Sci Technol 1986;40(6):284-6.

Oliveira LD, Carvalho CA, Valera MC, Koga-Ito CY, Jorge AO. Diffusion ability of endotoxin through dentinal tubules. Pesqui Odontol Bras. 2005a;19(1):5-10.

Oliveira LD, Jorge AO, Carvalho CA, Koga-Ito CY, Valera MC. In vitro effects of endodontic irrigants on endotoxins in root canals. Oral Surg Oral Med Oral Pathol Oral Radiol Endod 2007 [Epub ahead of print].

Oliveira LD, Leao MV, Carvalho CA, Camargo CH, Valera MC, Jorge Ao, et al. In vitro effects of calcium hydroxide and polymyxin $B$ on endotoxins in root canals. $J$ Dent 2005b;33(2):107-14.

Ørstavik D, Ford TRP. Essential endodontology. prevention and treatment of apical periodontitis.1a.ed. Oxford: Blackwell Science; 1998.

Pitts DL, Williams BL, Morton TH JR. Investigation of the role of endotoxin in periapical inflammation. J Endod 1982;8(1):10-8. 
Raisz LG, Nuki K, Alander CB, Craig RG. Interactions between bacterial endotoxin and other stimulators of bone resorption in organ culture. J Periodontal Res 1981;16(1):1-7.

Ramskold LO, Fong CD, Stromberg T. Thermal effects and antibacterial properties of energy levels required to sterilize stained root canals with an Nd:YAG laser. J Endod 1997;23(2):96-100.

Rietschel ET, Brade H. Bacterial endotoxins. Sci Am 1992;267(2):54-61.

Roslansky P F, Dawson ME, Novitsky TJ. Plastics endotoxins and the Limulus amebocyte lysate test. J Parenter Sci Technol 1991;45(2):83-8.

Ruff ML, Mcclanahan SB, Babel BS. In vitro antifungal efficacy of four irrigants as a final rinse. J Endod 2006;32(4):331-3.

Safavi KE, Nichols FC. Alteration of biological properties of bacterial lipopolysaccharide by calcium hydroxide treatment. J Endod 1994;20(3):127-9.

Safavi KE, Nichols FC. Effect of calcium hydroxide on bacterial lipopolysaccharide. J Endod 1993;19(2):76-8.

Schein B, Schilder H. Endotoxin content in endodontically involved teeth. J Endod 1975;1(1):19-21.

Schonfeld SE, Greening AB, Glick DH, Frank AL, Simon JH, Herles SM. Endotoxic activity in periapical lesions. Oral Surg Oral Med Oral Pathol 1982;53(1):82-7.

Schoop U, Kluger W, Moritz A, Nedjelik N, Georgopoulos A, Sperr W. Bactericidal effect of different laser systems in the deep layers of dentin. Lasers Surg Med 2004;35(2):111-6.

Seltzer S, Farber PA. Microbiologic factors in endodontology. Oral Surg Oral Med Oral Pathol 1994;78(5):634-45. 
Shetty N, Srinivasan S, Holton J, Ridgway GL. Evaluation of microbicidal activity of a new disinfectant: Sterilox 2500 against Clostridium difficile spores, Helicobacter pylori, vancomycin resistant Enterococcus species, Candida albicans and several Mycobacterium species. J Hosp Infect 1999;41(2):101-5.

Silva L, Nelson-Filho P, Leonardo MR, Rossi MA, Pansani CA. Effect of calcium hydroxide on bacterial endotoxin in vivo. J Endod 2002;28(2):94-8.

Silva LA, Leonardo MR, Assed S, Tanomaru Filho M. Histological study of the effect of some irrigating solutions on bacterial endotoxin in dogs. Braz Dent $\mathrm{J}$ 2004;15(2):109-14.

Siqueira Jr JF, De Uzeda M. Intracanal medicaments: evaluation of the antibacterial effects of chlorhexidine, metronidazole, and calcium hydroxide associated with three vehicles. J Endod 1997;23(3):167-9.

Siqueira Jr JF, Magalhães KM, Rôças IN. Bacterial reduction in infected root canals treated with $2.5 \% \mathrm{NaOCl}$ as an irrigant and calcium hydroxide/camphorated paramonochlorophenol paste as an intracanal dressing. No prelo, Corrected Proof, Available online 26 March 2007.

Siqueira Jr JF, Rocas IN, Alves FR, Santos KR. Selected endodontic pathogens in the apical third of infected root canals: a molecular investigation. J Endod 2004;30(9):638-43.

Siqueira Jr JF. Aetiology of root canal treatment failure: why well-treated teeth can fail. Int Endod J 2001;34(1):1-10.

Souza JIL. Análise "in vitro" da eficácia da impermeabilização da dentina radicular com verniz tipo copal, em dentes obturados com os cimentos N-Rickert e Sealer-26 e preparados para retentor intra-radicular, empregando método de infiltração e quantificação do nível de endotoxina [Tese Doutorado] São Paulo Faculdade de Odontologia da Universidade de São Paulo; 2000.

Strawn SE, White JM, Marshall GW, Gee L, Goodis HE, Marshall SJ. Spectroscopic changes in human dentine exposed to various storage solutions short term. J Dent 1996;24(6):417-23.

Sundqvist G, Johansson E, Sjogren U. Prevalence of black-pigmented bacteroides species in root canal infections. J Endod 1989;15(1):13-9. 
Sundqvist G. Associations between microbial species in dental root canal infections. Oral Microbiol Immunol 1992;7(5):257-62.

Tanomaru JM, Leonardo MR, Tanomaru Filho M, Bonetti Filho I, Silva LA. Effect of different irrigation solutions and calcium hydroxide on bacterial LPS. Int Endod J 2003;36(11):733-9.

Torabinejad M, Khademi AA, Babagoli J, Cho Y, Johnson WB, Bozhilov K, et al. A new solution for the removal of the smear layer. J Endod. 2003;29(3):170-5.

Tortora GJ, Funke BR, Case, LC. Microbiology: an introduction. $6^{\mathrm{a}}$ ed. Menlo Park: Benjamin/Cummings; 1998.

Trope M, Chow E, Nissan R. In vitro endotoxin penetration of coronally unsealed endodontically treated teeth. Endod Dent Traumatol 1995;11(2):90-4.

Twohy CW, Duran AP, Peeler JT. Extraction of bacterial endotoxin from medical devices. J Parenter Sci Technol 1986;40(6):287-91.

Wesselink PR, Thoden Van Velzen SK, Makkes PC. Release of endotoxin in an experimental model simulating the dental root canal. Oral Surg Oral Med Oral Pathol 1978;45(5):789-95.

White JM, Goodis HE, Marshall SJ, Marshall GW Sterilization of teeth by gamma radiation. J Dent Res 1994;73(9):1560-7.

Yamasaki M, Nakane A, Kumazawa M, Hashioka K, Horiba N, Nakamura H. Endotoxin and gram-negative bacteria in the rat periapical lesions. J Endod 1992;18(10):501-4. 
APÊNDICE A - Estatística descritiva. Determinação do tempo do experimento

\begin{tabular}{|c|c|c|c|}
\hline & $-1-$ & $-2-$ & $-3-$ \\
\hline Tamanho da amostra = & 13 & 19 & 19 \\
\hline Mínimo & 0.0030 & 0.0050 & 0.0040 \\
\hline Máximo & 0.0600 & 0.4270 & 0.2600 \\
\hline Amplitude Total & 0.0570 & 0.4220 & 0.2560 \\
\hline Mediana & 0.0150 & 0.0930 & 0.0750 \\
\hline Primeiro Quartil (25\%) & 0.0070 & 0.0555 & 0.0290 \\
\hline Terceiro Quartil (75\%) & 0.0230 & 0.1470 & 0.1490 \\
\hline Desvio Interquartílico & 0.0160 & 0.0915 & 0.1200 \\
\hline Média Aritmética & 0.0192 & 0.1289 & 0.0917 \\
\hline Variância & 0.0003 & 0.0142 & 0.0061 \\
\hline Desvio Padrão & 0.0183 & 0.1191 & 0.0779 \\
\hline Erro Padrão & 0.0051 & 0.0273 & 0.0179 \\
\hline Coeficiente de Variação & $95.11 \%$ & $92.40 \%$ & $84.86 \%$ \\
\hline Assimetria (g1) & 1.4628 & 1.4609 & 0.8516 \\
\hline Curtose (g2) & 1.3866 & 1.4698 & -0.4993 \\
\hline Média Harmônica = & 0.0080 & 0.0372 & 0.0296 \\
\hline $\mathrm{N}$ (média harmônica) $=$ & 13 & 19 & 19 \\
\hline Média Geométrica = & 0.0125 & 0.0800 & 0.0584 \\
\hline $\mathrm{N}$ (média geométrica $)=$ & 13 & 19 & 19 \\
\hline Variância (geom.) = & 1.5621 & 1.7752 & 1.6984 \\
\hline Desvio Padrão (geom.) = & 2.7550 & 3.1569 & \\
\hline
\end{tabular}


Análise estatística. Teste de Kruskal - Wallis. Determinação do tempo do experimento

\begin{tabular}{|c|c|c|c|c|}
\hline & Resultados & & & \\
\hline $\mathrm{H}=$ & 16.8478 & & & \\
\hline Graus de liberdade $=$ & 2 & & & \\
\hline (p) Kruskal-Wallis = & 0.0002 & & & \\
\hline $\mathrm{R} 1=$ & 151.5000 & & & \\
\hline $\mathrm{R} 2=$ & 622.5000 & & & \\
\hline $\mathrm{R} 3=$ & 552.0000 & & & \\
\hline $\mathrm{R} 1$ (posto médio) = & 11.6538 & & & \\
\hline $\mathrm{R} 2$ (posto médio) = & 32.7632 & & & \\
\hline $\mathrm{R} 3$ (posto médio) = & 29.0526 & & & \\
\hline Comparações (método de Dunn) & Dif. Postos & z calculado & z crítico & $\mathrm{p}$ \\
\hline Postos médios 1 e 2 & 21.1093 & 3.9450 & 2.394 & $<0.05$ \\
\hline Postos médios 1 e 3 & 17.3988 & 3.2516 & 2.394 & $<0.05$ \\
\hline Postos médios 2 e 3 & 3.7105 & 0.7693 & 2.394 & ns \\
\hline
\end{tabular}


APÊNDICE B - Estatística descritiva. Experimento

$\begin{array}{cccc} & \text { Controle positivo } & \text { Oscilatório } & \text { Helicoidal } \\ \text { Tamanho da amostra }= & 3 & 9 & 7 \\ \text { Mínimo } & 0.0330 & 0.0000 & 0.0000 \\ \text { Máximo } & 0.0630 & 0.0300 & 0.0160 \\ \text { Amplitude Total } & 0.0300 & 0.0300 & 0.0160 \\ \text { Mediana } & 0.0390 & 0.0010 & 0.0010 \\ \text { Primeiro Quartil (25\%) } & 0.0360 & 0.0000 & 0.0000 \\ \text { Terceiro Quartil (75\%) } & 0.0510 & 0.0030 & 0.0040 \\ \text { Desvio Interquartílico } & 0.0150 & 0.0030 & 0.0040 \\ \text { Média Aritmética } & 0.0450 & 0.0047 & 0.0036 \\ \text { Variância } & 0.0003 & 0.0001 & 0.0000 \\ \text { Desvio Padrão } & 0.0159 & 0.0097 & 0.0059 \\ \text { Erro Padrão } & 0.0092 & 0.0032 & 0.0022 \\ \text { Coeficiente de Variação } & 35.28 \% & 208.03 \% & 164.75 \% \\ \text { Assimetria (g1) } & 1.4579 & 2.7719 & 2.0352 \\ \text { Curtose (g2) } & --- & 7.9127 & 4.1140 \\ \text { Média Harmônica }= & 0.0418 & 0.0025 & 0.0023 \\ \text { N (média harmônica) }= & 3 & 5 & 4 \\ \text { Média Geométrica }= & 0.0433 & 0.0040 & 0.0037 \\ \text { Nesvio (média geométrica) }= & 3 & 5 & 4.9094 \\ \text { Variância (geom.) } & 1.0501 & 3.6512 & 3.3884\end{array}$


Análise estatística. Teste de Kruskal - Wallis. Experimento

Resultados

$H=$

7.2190

Graus de liberdade $=$

2

(p) Kruskal-Wallis =

0.0271

$\mathrm{R} 2=$

54.0000

R $3=$

76.5000

R 4 =

59.5000

$\mathrm{R} 2$ (posto médio) $=$

18.0000

R 3 (posto médio) =

8.5000

$\mathrm{R} 4$ (posto médio) =

8.5000

Comparações (método de Dunn)

$\begin{array}{cccc}\text { Dif. Postos } & \text { z calculado } & \text { z crítico } & p \\ 9.5000 & 2.5323 & 2.394 & <0.05 \\ 9.5000 & 2.4464 & 2.394 & <0.05 \\ 0.0000 & 0.0000 & 2.394 & \text { ns }\end{array}$

Postos médios 2 e 3

Postos médios 2 e 4

0.0000

0.0000 
APÊNDICE C - Estatística descritiva. Validação do controle positivo

\begin{tabular}{|c|c|c|}
\hline & Controle negativo & Controle positivo \\
\hline Tamanho da amostra = & 3 & 3 \\
\hline Mínimo & 0.0040 & 0.0330 \\
\hline Máximo & 0.0100 & 0.0630 \\
\hline Amplitude Total & 0.0060 & 0.0300 \\
\hline Mediana & 0.0070 & 0.0390 \\
\hline Primeiro Quartil (25\%) & 0.0055 & 0.0360 \\
\hline Terceiro Quartil (75\%) & 0.0085 & 0.0510 \\
\hline Desvio Interquartílico & 0.0030 & 0.0150 \\
\hline Média Aritmética & 0.0070 & 0.0450 \\
\hline Variância & 0.0000 & 0.0003 \\
\hline Desvio Padrão & 0.0030 & 0.0159 \\
\hline Erro Padrão & 0.0017 & 0.0092 \\
\hline Coeficiente de Variação & $42.86 \%$ & $35.28 \%$ \\
\hline Assimetria (g1) & 0.0000 & 1.4579 \\
\hline Curtose (g2) & --- & --- \\
\hline Média Harmônica = & 0.0061 & 0.0418 \\
\hline $\mathrm{N}$ (média harmônica) = & 3 & 3 \\
\hline Média Geométrica = & 0.0065 & 0.0433 \\
\hline $\mathrm{N}$ (média geométrica) $=$ & 3 & 3 \\
\hline Variância (geom.) = & 1.0971 & 1.0501 \\
\hline Desvio Padrão (geom.) = & 1.5870 & 1.3989 \\
\hline
\end{tabular}


Análise estatística. Teste de Kruskal - Wallis. Validação do controle positivo 1 positivo - 2 negativo

$\begin{array}{cc} & \text { Resultados } \\ \mathrm{H}= & 3.8571 \\ \text { Graus de liberdade }= & 1 \\ \text { (p) Kruskal-Wallis }= & 0.0495 \\ \mathrm{R} 1= & 6.0000 \\ \mathrm{R} 2= & 15.0000 \\ \mathrm{R} 1 \text { (posto médio) }= & 2.0000 \\ \mathrm{R} 2 \text { (posto médio) }= & 5.0000\end{array}$

$\begin{array}{ccccc}\text { Comparações (método de Dunn) } & \text { Dif. Postos } & \mathrm{z} \text { calculado } & \mathrm{z} \text { crítico } & \mathrm{p} \\ \text { Postos médios 1 e } 2 & 3.0000 & 1.9640 & 1.96 & <0.05\end{array}$ 
APÊNDICE D - Análise estatística. Teste de Kruskal - Wallis. Comparação do controle negativo e os grupos experimentais

\section{Resultados}

$\begin{array}{lc}\mathrm{H}= & 3.2105 \\ \text { Graus de liberdade }= & 2 \\ \text { (p) Kruskal-Wallis }= & 0.2008\end{array}$

Nível de significância foi $5 \%(p \leq 0,05)$

APÊNDICE E - Primeira medida após 24 horas. Não ocorreu passagem de endotoxinas. Inicio da passagem de endotoxinas

\begin{tabular}{cccc}
\hline controle negativo & controle positivo & oscilatório & helicoidal \\
\hline 0.005 & 0.053 & 0.028 & $\mathrm{SL}$ \\
0.002 & 0.003 & 0.003 & $\mathrm{SL}$ \\
0.006 & $\mathrm{SL}$ & 0.060 & $\mathrm{SL}$ \\
& & 0.023 & $\mathrm{SL}$ \\
& 0.018 & $\mathrm{SL}$ \\
& $\mathrm{SL}$ & 0.009 \\
& 0.015 & 0.003 \\
& & 0.013 & 0.007 \\
& & 0.015 & $\mathrm{SL}$ \\
\hline
\end{tabular}

SL: Sem Leitura 
APÊNDICE F - Segunda medida após 48 horas

\begin{tabular}{cccc}
\hline controle negativo & controle positivo & oscilatório & helicoidal \\
\hline 0.010 & 0.079 & 0.115 & 0.016 \\
0.006 & 0.361 & 0.073 & $\mathrm{C}$ \\
0.008 & 0.005 & 0.327 & 0.013 \\
& & 0.115 & $\mathrm{C}$ \\
& 0.134 & 0.090 \\
& 0.093 & 0.175 \\
& & 0.427 & 0.079 \\
& 0.033 & 0.038 \\
& & 0.160 & 0.117 \\
\hline
\end{tabular}

C: Contaminação

APÊNDICE G - Terceira medida após 72 horas. Inicio do decréscimo da passagem de endotoxinas

\begin{tabular}{cccc}
\hline controle negativo & controle positivo & oscilatório & helicoidal \\
\hline 0.005 & 0.202 & 0.073 & 0.022 \\
0.007 & 0.191 & 0.075 & $\mathrm{C}$ \\
0.010 & 0.004 & 0.260 & 0.016 \\
& 0.119 & $\mathrm{C}$ \\
& 0.179 & 0.077 \\
& 0.036 & 0.084 \\
& 0.203 & 0.051 \\
& 0.017 & 0.019 \\
& & 0.078 & 0.037 \\
\hline
\end{tabular}

C: Contaminação 
APÊNDICE H - Quarta medida após irradiação com laser de Nd:YAG

\begin{tabular}{cccc}
\hline controle negativo & controle positivo & oscilatório & helicoidal \\
\hline 0.004 & 0.033 & 0.000 & 0.000 \\
0.007 & 0.063 & 0.001 & $\mathrm{C}$ \\
0.010 & 0.039 & 0.030 & 0.002 \\
& & 0.000 & $\mathrm{C}$ \\
& 0.006 & 0.016 \\
& 0.000 & 0.001 \\
& 0.000 & 0.006 \\
& 0.003 & 0.000 \\
& 0.002 & 0.000 \\
\hline
\end{tabular}

C: Contaminação 
ANEXO A - Parecer do Comitê de Ética em Pesquisa

\section{Faculdade de Odontologia}

Universidade de São Paulo

\section{PARECER DE APROVAÇÃO \\ Protocolo 174/04}

O Grupo de Trabalho indicado pelo Comitê de Ética em Pesquisa, APROVOU o protocolo de pesquisa "Análise da ação do laser de Nd: YAG sobre endotoxinas em dentina de canais radiculares", de responsabilidade do Pesquisador José Ricardo de Freitas Archilla, sob orientação da Profa. Dra. Márcia Martins Marques.

Tendo em vista a legislação vigente, devem ser encaminhados a este Comitê relatórios anuais referentes ao andamento da pesquisa e ao término cópia do trabalho em "cd". Qualquer emenda do projeto original deve ser apresentada a este CEP para apreciação, de forma clara e sucinta, identificando a parte do protocolo a ser modificada e suas justificativas.

São Paulo, 20 de outubro de 2004

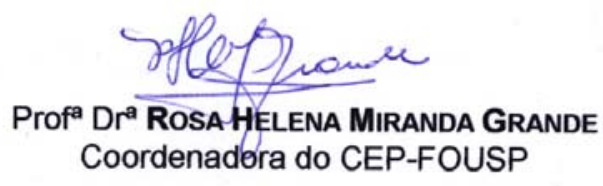

Av. Prof. Lineu Prestes, 2227 - Cidade Universitária "Armando de Salles Oliveira" CEP 05508-900 Săo Paulo - SP Diretoria Telefax (011) 38140062 - $30917817 / 60$ 
ANEXO B - Certificado de Irradiação de Produto

\section{CERTIFICADO DE IRRADIAÇÃO DE PRODUTO}

\section{№ : CTR-CI-FO-004/07}

O CENTRO DE TECNOLOGIA DAS RADIAÇÕES (CTR) do INSTITUTO DE PESQUISAS ENERGÉTICAS E NUCLEARES - IPEN certifica que os produtos abaixo relacionados e solicitado por meio de e-mail da Faculdade de Odontologia, FOUSP, datado de 23 de fevereiro de 2007, foram tratados em 27/02/2007 por radiação gama (Cobalto-60) no irradiador multipropósito e receberam a dose média de 30,5 kGy.

Relação de produtos:

14 embalagens plásticas contendo materiais de estudo para tese de doutorado: "AÇ̃̃O DO LASER DE Nd:YAG SOBRE ENDOTOXINAS EM DENTINA DE CANAIS RADICULARES" do aluno José Ricardo Archilla da FO-USP, departamento de Dentística.

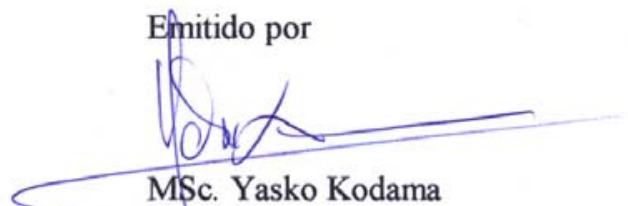

CTRD

Data: 27/02/07

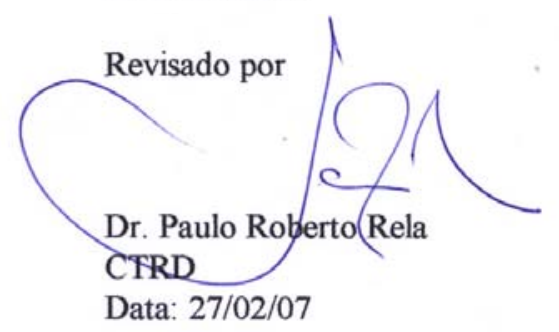




\section{ANEXO C - Certificado de Análise de Endotoxina}

\section{ASSOCIATESOF}

Spectalists in Endotaxin and Gucan Detection

Technician: S. Chandler

Date of Test: 07/21/2006

Instrument: Pyros Kinetix
Reference Standard Endotoxin (RSE); lot \#EC-6-2, 10,000 EU*/vial

Control Standard Endotoxin (CSE): lot \#102, $0.5 \mu \mathrm{g} / \mathrm{vial}$

Pyrotello-T: lot \#506-03-386-T, Exp: 20 MAR 2011

Procedure:

RSE: one vial; standard concentrations in four-fold serial dilutions in duplicate. See results section for the range of RSE concentrations used to measure the potency.

CSE: four vials; standard concentrations that are expected to give onset times within the range of onset times that define the RSE standard curve, in duplicate. Standards falling outside the range of onset times defined by the RSE standard curve will be excluded from calculations.

\section{Calculations:}

RSE Standard Curve Equation: $Y=3.052+(-0.2197) X ;|r|=0.985$

CSE concentrations in $\mathrm{EU} / \mathrm{ml}$ were calculated by substituting the mean CSE log onset times, that fell within the range defined by the RSE times of onset, into the RSE standard curve equation. The potency at each

CSE concentration is the CSE concentration in $\mathrm{EU} / \mathrm{ml}$ divided by the nominal CSE concentration in $\mathrm{ng} / \mathrm{ml}$.

\begin{tabular}{lcc}
\multicolumn{2}{c}{ CSE Concentration } & \\
$\mathrm{ng} / \mathrm{ml}$ & EU/ml & Potency (EU/ng) \\
0.08000 & 0.9152 & 11.44 \\
0.02000 & 0.3478 & 17.39 \\
0.00500 & 0.0982 & 19.65 \\
0.00125 & 0.0215 & 17.23 \\
0.00031 & 0.0038 & 12.04
\end{tabular}

Mean potency $=15.55 \mathrm{EU} / \mathrm{ng}$

See Guideline on Validation of the Limulus Amebocyte Lysate Test as an End-product Endotoxin Test for Human and Animal Parenteral Drugs, Biological Products, and Medical Devices, Appendix C Section C., for details on performing these calculations. The numbers on this report have been rounded to three significant figures. The potency was calculated before rounding.

Results:

Potency of CSE $=15.55 \mathrm{EU} / \mathrm{ng}$ or $15.55 \mathrm{IU} / \mathrm{ng}$; concentration of CSE/vial $=(\mathrm{EU} / \mathrm{ng}) \times(\mathrm{ng} / \mathrm{vial})=15.55 \times$ $500=7,775 \mathrm{EU} /$ vial or $7,775 \mathrm{IU} / \mathrm{vial}$.

Within the error of the test, the calculated potency may be expressed as $16.0 \mathrm{EU} / \mathrm{ng}$ or $16.0 \mathrm{IU} / \mathrm{ng}$; $8,000 \mathrm{EU} / \mathrm{vial}$ or $8,000 \mathrm{IU} / \mathrm{vial}$.

This potency is valid over the range of the RSE concentrations used to measure the potency: 4.0 to $0.001 \mathrm{EU} / \mathrm{ml}$.

The RSE, EC-6-2 is the same as that available from USP as lot G2B274 and has been adoptod by the Exper Committee on Biological Standardization of the World Health Organization as the Second International Standard $\left(2^{\mathrm{e}} \mathrm{IS}\right.$ ). Vials from this lot, obtained from FDA or USP, have unitage expressed as 10,000 EU/vial. Vials obtained from WHO have unitage expressed as 10,000 IU/vial (Poole, S., P. Dawson, and R.E. Gaines Das. 1997. Second international standard for endotoxin: calibration in an international collaborative study. J. Endotoxin Res. 4(3):221-231).

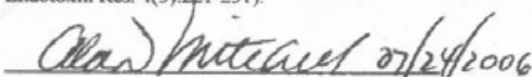

Quality Control/Quality Assuranct Dept.

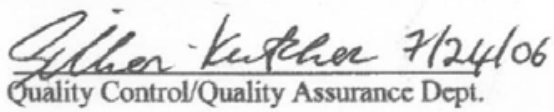

Potency subject to change, within the error of the test, at any time. If the potency is re-determined, and is within twofold of the previous value, the previous potency is still valid. Form QC001-0.5, Rev. 007, Sep 2005 